\title{
Improved Probabilistic Modeling of Multi-Site Fatigue Cracking
}

\author{
Abdallah Al Tamimi ${ }^{1}$, Mohammad Modarres ${ }^{1}$ \\ ${ }^{1}$ Unicersity of Maryland, Center of Risk and Reliability, College Park, Maryland, 20742, USA \\ Altamimi@umd.edu \\ Modarres@umd.edu
}

\begin{abstract}
The purpose of this paper is to investigate the effect of fatigue, in the presence of neighboring cracks, and to integrate that into a model that could be used to predict crack growth. A total of 20 fatigue experiments were performed at different loading conditions using dog-bone samples of API-5L grade B carbon steel containing neighboring cracks. The impact of the neighboring cracks dimensions and the loading conditions on the interaction, coalescence and growth of cracks were investigated. A design of experiment approach to study neighboring cracks interactions and growth in carbon steel materials is also presented. Simulation efforts were performed to assess the Stress Intensity Factor (SIF) around neighboring cracks. Models discussing how the SIF of single semi-elliptical crack could be corrected to account for the neighboring cracks interaction were discussed in order to better understand the fatigue behavior. A combination of these models was integrated to find the SIF values necessary for the probabilistic life prediction modeling purposes. Finally, a multi-site fatigue crack growth rate model was developed and its parameters including their uncertainties were estimated. A Bayesian approach was adopted to perform uncertainty characterization and model validation.
\end{abstract}

\section{INTRODUCTION}

The purpose of this study is to investigate and model the interaction of neighboring cracks under fatigue loading and integrate that into a life prediction model that could be used to estimate the remaining life of engineering structures. As such, development of a method that accounts for applicable and realistic cracks interaction, validated with acceptable modeling error, is the main objective of the study.

Based on the literature review performed in this research, a large portion of the work done in modeling crack

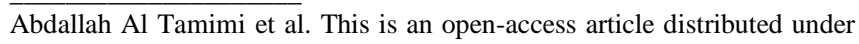
the terms of the Creative Commons Attribution 3.0 United States License, which permits unrestricted use, distribution, and reproduction in any medium, provided the original author and source are credited. propagation modeling has been directed towards investigating single crack growth. It was ostensible that there is a need to acquire more information about neighboring cracks growth. Hence, the prime objective of this research is to develop further understanding of modeling fatigue of neighboring cracks through the following steps: adopt a degradation model for fatigue crack growth by investigating the most relevant physics based models available in the literature, identify the associated model variables and uncertain parameters in the adopted model, gather prior data/information of the adopted model uncertain parameters, develop an experimental test method to provide the scatter of data required for both updating the uncertain parameters and validating the final model proposed, perform necessary simulations in order to compute the SIF around the neighboring cracks, identify a Bayesian updating approach to update the model uncertain parameters on the experimental and simulation evidence data gathered and finally quantify the model uncertainties and validate it.

This paper have illustrated an improved experimental layout and procedure to investigate multi-site fatigue in carbon steel materials which provided a better understanding of the effect of neighboring cracks dimensional variability on their interaction, coalescence and growth process. Also, it has broadened the state of the art on the effect of different loading conditions on crack interaction, coalescence and growth process. An improved understanding of the ligament failure phenomena when neighboring cracks achieve coalescence was also discussed. Finally, a new model of crack growth that accounts for neighboring cracks interaction and coalescence was proposed.

\subsection{Linear Elastic Fracture Mechanics}

The problem under investigation is a linear elastic fracture mechanics problem, where the elastic stress intensity factor (K) and Paris law for growth are applicable. According to (Stephens, Fatemi, Stephens, \& Fuchs, 2000) there are some constraints when using linear elastic fracture mechanics (LEFM), however, these constraints do not apply directly to 
the cases investigated in this work. Stephens et. al. (2000) indicated that for LEFM concepts to hold, the nominal stresses applied in a specific cracked plane should be less than $80 \%$ of the yield strength. Also, the same source added that the plastic distance ahead of the crack tip, $r_{y}$, should be less than $1 / 8^{\text {th }}$ of the cracked plane thickness and the untracked ligament along the plane of the crack.

According to (Bayley, 1997), for most metallic materials, the size of the inelastic region adjacent to the crack tip is relatively small in comparison with the crack size. For that reason, the amount of material experiencing inelastic behavior is small compared to the overall elastic state of the sample or component. Consistent with (Alseyabi, 2009), fatigue stresses applied to a component leads to a plastic deformation zone ahead of the advancing fatigue crack. When this resulting zone is very small compared to the elastic field, LEFM solutions provide a suitable description for fatigue fracture. In this paper, Mode I type of loads will be considered in studying the impact of fatigue loads on cracks coalescence and interaction.

\subsection{Crack Shape in Fatigue}

Understanding crack growth behavior and development is essential when it comes to life prediction and monitoring of structures and components. According to (Paris \& Erdogan, 1963), crack will propagate in the direction of maximum stress intensity. Also, consistent with (Lin \& Smith, 1995), regardless of the initial crack shape and size, the crack will always grow towards an equilibrium shape before it grows in different directions.

Three categories of flaws can be found in operating engineering structures: a single flaw (e.g., semi-elliptical cracks, corner cracks, circular crack and embedded cracks), neighboring interacting cracks (i.e., the focus of this research work) and multi-element flaws which characterize the effect of a flaw in a component on another flaw in a different component.

According to (Leek \& Howard, 1996), surface cracks can be, at least initially, irregular shapes and orientations. However, a standard practices is to characterize a surface crack by projecting it onto the plane normal to the principal stress and assume the crack to be semi-elliptical in shape, having the dimensions of the rectangle that fully encloses the flaw. The characterized crack can be identified by its radius (r) and depth (a).

Another important aspect of characterizing neighboring cracks is the distance between the planes of the cracks. When this distance approaches zero, meaning that the two cracks exists on the same plane, then there are two coplanar cracks. Otherwise the neighboring cracks will be noncoplanar cracks. The focus of this research is semi-elliptical coplanar cracks as illustrated in Figure 1:

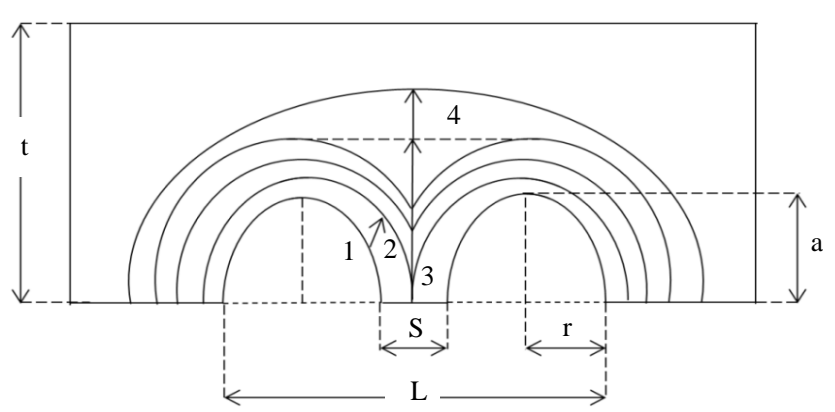

Figure 1: Neighboring cracks nomenclature illustration along with the neighboring cracks growth stages: 1 :

Separate phase 2: Interaction phase 3: Re-characterization phase 4: Post-coalescence phase (DeBartolo \& Hillberry, 1998)

(Nuhi, Abu Seer, Al Tamimi, Modarres, \& Seibi, 2011) investigated the dimensional growth of corrosion pits and their density under different corrosive conditions. It was found that as temperature and exposure time to the corrosive medium increased, a significant increase in pit size and density was observed. Nuhi et. al. (2011) also found that the variation in pit dimensions had an average standard deviation of almost $20 \%$ of the recorded pit depth.

\subsection{SIF of a Single Semi-Elliptical Crack}

Many efforts were directed towards studying single crack SIF. One of the first single-crack SIF approximations was developed by (Irwin, 1962). Many approximations followed Irwins' work taking the form of both discrete values and continuous equations and are discussed by (Leek, 1990).

A leading SIF approximate expressions for a single semielliptical crack was proposed by (Newman \& Raju, 1979) and (Newman \& Raju, 1981) due to their adequate accuracy, ease of use, and wide ranging applicability. Newman and Raju (1979, 1981), compared their Finite Element Method (FEM) solutions for semi-elliptical surface cracks to experimentally determined fracture data. According to Leek and Howard (1996), Newman and Raju ranked the highest amongst other solutions in terms of accuracy. Their solutions correlated with $95 \%$ of the data analyzed within $\pm 10 \%$ error. According to Leek (1990), an examination of different solutions of the SIF of a single crack shows that the solution provided by Newman and Raju $(1979,1981)$ has a good accuracy and is applicable over a wide range of semi-elliptical cracks.

\subsection{Cracks Interaction and Coalescence}

Numerous researchers have studied crack interaction and coalescence including: (O'Donoghure, Nishioka, \& Atluris, 1984), (Twaddle \& Hancock, 1988), (Kishimoto, Soboyejo, Smith, \& Knott, 1989), (Soboyejo \& Knott, 1990), (Leek, 1990), (Leek \& Howard, 1994), (Harrington, 1995) and (Leek \& Howard, 1996). Most of their research was directed 
toward understanding the coalescence mechanism of two neighboring surface cracks.

According to Leek and Howard (1994) and DeBartolo and Hillberry (1998), the process of two adjacent and coplanar cracks interaction, coalescence and growth is governed by four main stages as illustrated in Figure 1: separate phase, interaction phase (i.e., pre-coalescence phase), recharacterization phase and the post-coalescence phase.

During phase one of interaction, the neighboring cracks are treated independently meaning that they have no impact on each other's SIF. Also, in phase three, one single enveloping crack is formed and the single crack SIF analysis is used. However, second phase shows the interaction stage where the proximity of neighboring cracks affects their respective SIF values. Experimental data and finite element simulations done by Kishimoto et. al. (1989) and Soboyejo and Knott (1990) showed that the concave crack front in phase three has a high SIF value approximated by twice the SIF around the rest of the cracks due to the rapid failure of the ligament between the two cracks. This rapid failure of the ligament explains also the fast transition from phase two to phase three in this process.

Researchers have yet to reach an agreement on a threshold that indicates the start of crack coalescence. According to (Forsyth, 1983), two cracks will grow together when the plastic zones around the cracks first overlapped. (Chang, 1982) assumed that the cracks would coalesce when the distance between the two cracks was less than $7 \%$ of their total length. (Chaussumier, Shahzad, Mabru, Chieragatti, \& Rezai-Aria, 2010) proposed that the coalescence of cracks is detected when their lengths increased by its crack tip when the plastic zone is large enough to interact with other neighboring cracks. (Melin, 1983) stated that two neighboring cracks don't meet tip to tip but instead deviate slightly and meet either sub-surface or by a small tear at the surface. According to Leek and Howard (1994), there are three main factors that affect crack interaction and coalescence: Separation distance between neighboring cracks, shape and relative size of each crack and the thickness of the section in which the cracks lie.

According to Leek and Howard (1996), when two coplanar cracks grow towards each other, before the cracks meet, either the SIF at the tip of closet proximity will reach the fracture toughness of the material leading to failure of the ligament between the cracks, or the plastic zones around the crack tips will come together invalidating the elastic analysis. Moreover, (Melin, 1983) added, when the cracks grow towards each other, they tend to avoid meeting directly. He showed analytically that it is energetically unfavorable for them to do so. Therefore, that advocates that the crack tips will deviate as if to grow past each other when they become close and join up by tearing of the ligament between the places of the crack tips. In order to simplify such situations, the failure of a certain engineering structure including interacting cracks could be predicted by setting a certain safety requirement like:

- Sudden increase in the SIF that implies the completion of the coalescence process and the formation of a single enveloping crack of a significant increase in dimension

- Crack front concave shape change to a convex shape caused by the ligament failure

- Surface cracks linkage

- Cracks fronts growth rate

\subsection{Assessment Methods of Cracks Interaction}

Different assessment methods of neighboring crack interaction and coalescence have been investigated in order to identify a method that is reliable and reasonably conservative to further understand the phenomenon from a reliability/integrity stand point. Neglecting the effect of neighboring crack interactions on the SIF could lead to an overly conservative life prediction model and assessment of structure integrity. Leek and Howard (1994) compared models that did not account for crack interactions and found that the safety margins achieved by such models induce overly conservative results, that under-predicts the true life, of up to $37 \%$.

According to Leek and Howard (1996), the ASME boiler and pressure vessel code(ASME, 1992), section XI, articles IWA-3000 and IGA-3000, and the BSI PD6493(BSI, 1991) are considered the most widely known methods for assessing interacting surface cracks. But, according to Leek, (1990) and Leek \& Howard (1994) and after tentatively investigating these methods both theoretically and practically, it was found that these models yield unrealistic overly conservative and perhaps unsafe crack growth predictions as it assumes a geometric condition to define crack coalescence excluding the impact of the different crack interaction and coalescence stages on the SIF along the crack front. Moreover,Leek and Howard (1994) added that both model accuracy and justification of their methods are unknown.

Another widely accepted assessment method of interacting neighboring cracks was proposed by (Iida, 1983). The method neglects neighboring cracks interaction by having no measure of interaction influence on the SIF in its analysis. When the cracks inner tips are predicted to touch, an immediate semi-elliptical enveloping crack drawn through the outer tips of the two coalescing cracks and through the deepest point of the deeper crack is assumed. This method was used in the literature as a basis for both experimental and simulation work by many researchers including Kishimoto et. al. (1989) and Soboyejo and Knott (1990). 
According to Leek and Howard (1996), the method proposed by Iida (1983) is a simple and realistic assessment method of neighboring cracks growth. However, it is not clear whether this method safely accounts for interaction on its own or whether safe assessments are obtained due to other factors in the growth calculations such as SIF approximations or even the material constants used.

Two of the widely used assessment methods of interacting neighboring cracks were developed by Leek and Howard (1994). Both methods were based on quantifying crack interaction and incorporating this quantification into the SIF and fatigue crack growth calculations. This Crack Interaction Factor (CIF) was widely studied using finite element and numerical analysis by many researchers including Murakami et. al. (1981), Murakami et al. (1982), O'Donoghue et al. (1984), Leek (1990) and Leek and Howard (1994). The first method developed by Leek and Howard (1994) (i.e., denoted by Leek and Howard I) was based on developing the crack interaction factor, which is considered a correction factor that takes into account the effect of neighboring cracks on the SIF. Crack interaction leads to an increase in the SIF values of neighboring cracks when compared to a single crack value. The SIF was corrected when neighboring cracks interact and coalesce as follows:

$$
S I F_{\text {neighboring cracks }}=\gamma \times S I F_{\text {single crack }}
$$

Where the cracks interaction factor (CIF) is defined as follows:

$$
\gamma=\frac{\mathrm{K}_{\mathrm{I}}^{\prime}}{\mathrm{K}_{\mathrm{I}}}
$$

The CIF used in this method was found using the solutions of (Erdogan, 1962) and (Yokobori, Ohashi, \& Ichikawa, 1965) for the elastic interaction factors of through cracks in an infinite plane under tensile load. Leek and Howard (1994) corrected these CIF values in order to use it for neighboring semi-elliptical surface cracks. However, as the original CIF work addresses through cracks, this method has insignificant emphasis on the crack front CIF, while it focuses more on the CIF at the crack tips. Moreover, this method can be cumbersome for crack growth calculations as it has many different calculation steps. The CIF is recalculated after each increment of growth, when the cracks are predicted to touch, a single enveloping crack is immediately assumed, and the CIF is not calculated anymore.

Leek and Howard (1996) developed another assessment method (i.e, Leek and Howard II). This method is straightforward and conservative. Leek and Howard II used the same CIF concept discussed in their previous model. However, this model was based on developing interaction factor values associated with specific dimensional criteria describing crack interaction and geometrical development. The method proposes a percentage increase in the SIF of the crack when having neighboring cracks versus existing independently. This percentage increase in the SIF is applied uniformly to all SIF values of the two cracks at a specific geometrical condition until the two cracks touch forming a single enveloping crack.

However, since the CIF approaches infinity when cracks become close and at a certain separation distance between the two cracks, the maximum SIF obtained by the use of CIF becomes larger than that obtained by assuming an enveloping crack. For that reason and in this paper, this point is considered as when the ligament fails between the two cracks forming the enveloping crack. So, the SIF values will be equated at this point to avoid any misleading results or confusion. Leek and Howard solutions were based on integrating Newman and Raju (1979-1981) SIF solutions for single semi-elliptical cracks along with Erdogan (1962) and Yokobori et. al. (1965) solutions for the CIF. Nevertheless, the CIF solutions proposed covers identical cracks. (Savin, 1981) has proposed solutions for the CIF for non-identical cracks.

The modeling work in this research was formulated based on a combination of conclusions provided by the previously discussed models. Fundamentally, Newman and Raju (1979-1981) SIF solutions for a single semi-elliptical crack, neglecting interactions model of Iida (1983) and the CIF model of Leek and Howard (1996) were used to formulate a model that could be realistic and practical for engineering structures health monitoring and management.

\section{EXPERIMENTAL WORK}

The main purpose of performing the fatigue testing was to study the fatigue properties of the material with interacting cracks, understand the impact of the neighboring cracks dimensions, evaluate the impact of the loading conditions on the cracks interaction and propagation, and finally gather data for the life prediction model development and validation. The experimental work provides information about the impact of the neighboring cracks dimensional variability on cracks growth, coalescence and failure.

This section shows a novel approach for investigating neighboring cracks growth and coalescence which is simple and feasible. The method developed is straight forward and does not require stopping the test at different number of cycles to measure the crack depth and determine the number of cycles to achieve coalescence. This leads to a major reduction in the number of samples and tests required to gather the data required for the modeling efforts.

\subsection{Testing material}

The material used in the fatigue testing was API-5L Grade $\mathrm{B}$, which is used in the construction of some transport pipelines. An energy dispersive X-ray spectroscopy (EDS) analysis was performed to the samples in order to 
characterize the elemental composition of the material as shown in Table 1:

Table 1: Elemental composition of API-5L Grade B

\begin{tabular}{|l|l|l|l|l|l|l|l|}
\hline Element & $\mathrm{Si}$ & $\mathrm{Cr}$ & $\mathrm{Mn}$ & $\mathrm{Fe}$ & $\mathrm{Co}$ & $\mathrm{Cu}$ & Total \\
\hline Weight \% & 0.18 & 0.20 & 0.86 & 82.35 & 0.41 & 0.09 & 84.09 \\
\hline Atomic \% & 0.44 & 0.26 & 1.04 & 97.71 & 0.47 & 0.09 & - \\
\hline
\end{tabular}

Moreover, in order to define the precise yield strength of the material for an accurate testing conditions determination, a tensile test was performed. The yield strength was estimated as $300 \mathrm{MPa}$.

\subsection{Testing samples}

Specimens with two adjacent initial cracks, simulating material defects and flaws, were considered for the crack coalescence experiments. The rectangular dog-boned shaped specimens have a thickness $t$ and width $2 \mathrm{~W}$. The samples were machined from an API-5L Grade B carbon steel that is typically used in the oil and gas industry. Figure 2 illustrates the dimensions of the samples that were designed according to the ASTM standard E466-07:

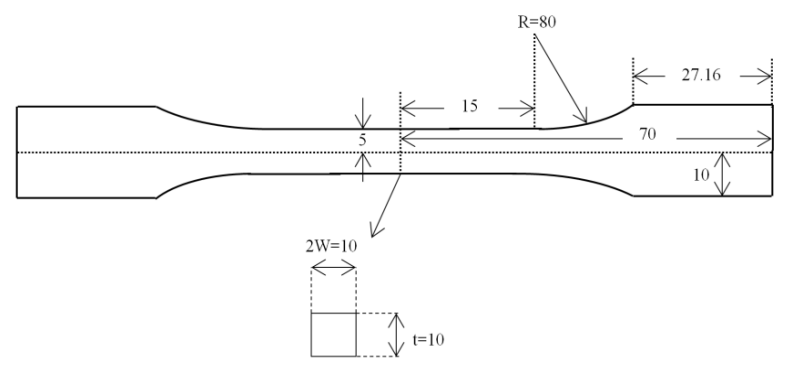

Figure 2: Sample dimension, all dimensions are in $\mathrm{mm}$, sample thickness is $10 \mathrm{~mm}$

The material and the samples machining was done in Metal Sample which specializes in manufacturing standard testing coupons and samples different types of tests using the latest metal cutting technologies.

\subsection{Notches design}

The samples were notched in order to simulate material defects and flaws. The notches were designed according to the ASTM standard E740/E740M and machined using an electric discharge machining (EDM). EDM is usually used to induce notches, as it is a firm machining option for manufacturing geometrically complex and hard material parts that are difficult to machine by conventional machining processes (Ho \& Newman, 2003). Other machining options include using slit saw to induce the initial notches Leek and Howard (1996), however, such techniques induce unnecessary residual stresses around the notch and has less accuracy and precession.

Looking at the cross section of the test specimen, the notches are semi-elliptical in shape with a thickness of 0.1 $\mathrm{mm}$, this geometry will assure a vertical growth of the crack, which leads to an idealized interaction between the two cracks.

As corrosion pits are considered major flaws in oil pipelines and other similar structures, the geometry of such flaws were considered for the experimental work. Using the findings of Nuhi et al. (2011), the variation of pits sizes resulting from exposure a carbon steel material to different corroding environments showed that the maximum average pit size was $0.0163 \mu \mathrm{m}$ with a standard deviation of 0.0032 $\mu \mathrm{m}$, i.e. $20 \%$ of the recorded depths mean value. The design of the notches in this work was based on increasing/decreasing each of the notch dimensions by one and two standard deviation in order to investigate the impact of the initial flaws size on crack growth and understand the significance of the dimensional variability between the neighboring cracks on the overall crack growth.

In this experimental work, the notches are semi-elliptical and coplanar. Three main variables were considered for designing the neighboring cracks notches: depth, diameter and spacing. Eleven different notch combinations, a sample is illustrated in Figure 3, were considered in order to investigate the impact of the initial cracks dimensional variability on crack propagation. However, the dimensions were amplified for accelerated testing purposes. For simplification and reference purposes, each notch geometric shape was given a code. The parameter $\mu$ is the initial notch size predetermined for accelerated testing purposes and the parameter $\sigma$ is the standard deviation, which is $20 \%$ of $\mu$. All experiments were compared to the reference geometry a_ $(\mu / \mu)$ for clarification purposes

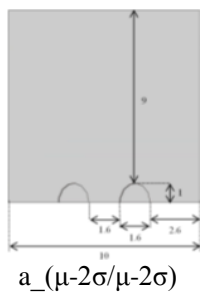

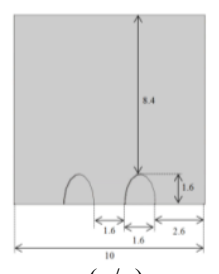

a_ $(\mu / \mu)$

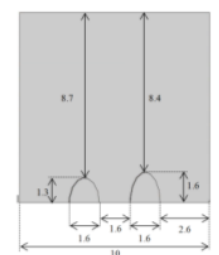

a_ $(\mu-\sigma / \mu)$

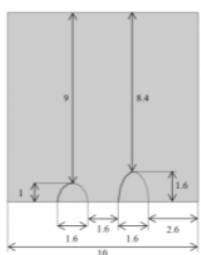

a_ $(\mu-2 \sigma / \mu)$
Figure 3: A sample of the cracks notch geometries used in the experimental work $(\mathrm{mm})$

\subsection{Experimental procedure}

Determining the number of cycles required for crack interaction, coalescence and failure are essential outcomes of the experimental work. This data will be the building blocks of the probabilistic life prediction model describing crack coalescence phenomenon. For that reason, a comprehensive experimental plan was designed to cover a wide range of crack geometries and loading conditions.

The effect of three main variables on cracks interaction, coalescence and growth: cracks dimensions, applied load and the loading ratio were investigated. The samples with 
the variable dimensions were tested under constant loading conditions. However, one specific geometry, a_ $(\mu / \mu)$, was tested under multiple stresses and loading ratios. A total of 19 fatigue tests, including four duplicate tests, were performed using the standard dog bone samples. The specimens were tested under constant amplitude uniaxial loading. The fatigue cycles consisted mainly of loading blocks and marker blocks. The loading blocks are the primary reason for crack propagation. On the other hand, the marker blocks were primarily used as a benchmarking technique to show crack shape progression during the fatigue testing. This allowed for a better understanding of the nature of interactions between the two cracks.

According to (Willard, 1997), one of the methods to monitor the fatigue crack front history after testing is to use the marker bands technique. Willard (1997) defined marker bands as groups of microscopic striations that when generated in the proper fashions are readily identifiable by optical and scanning electron microscopy. The marker block consists of load cycles with the same maximum stress applied; however, the minimum stress was increased to $80 \%$ of the maximum stress. According to (Terrell, 1988), it was observed that marking block with high stress ratio yields a better marking impression and visibility. A typical loading ratio used in marker blocks varies from 0.5 to 0.8 .

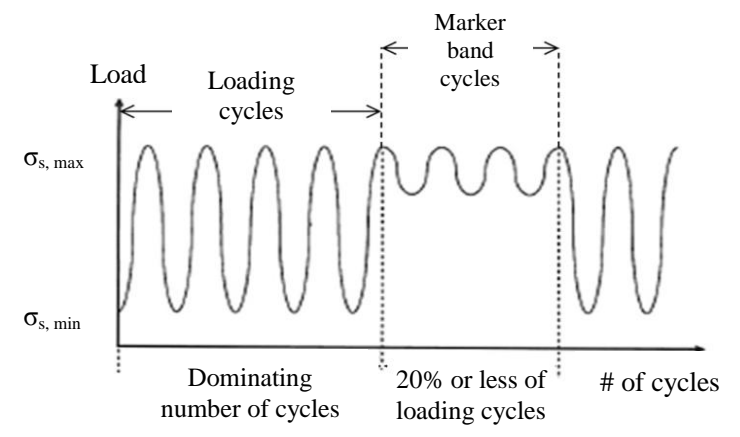

Figure 4: Plot of number of cycles versus applied load, a load patter illustration of the maker band technique, Terrell (1988)

Other researchers like Leek and Howard (1996) stated that changing either the loading ratio or the frequency could induce marker bands. However, as there is still a debate in the literature on the frequency effect on crack growth, this research used variable loading ratio to induce the marker bands.

The loading cycle was sinusoidal in waveform with a frequency of $2 \mathrm{~Hz}$. According to Terrell (1988), for API-5L grade B or A106, there is no effect of cyclic frequency on the fatigue life of notched samples at room temperature. The experiments were carried out at room temperature in air and fatigued on an MTS 311.11 load frame. The machine is of a variable capacity of up to $100 \mathrm{kN}$. An Instron 8800 controller controlled the load sequences used in the experiments. A real time optical microscope was used to monitor the surface crack length during the fatigue process.

Figure 5 illustrates the experimental layout and the microscope positioning.

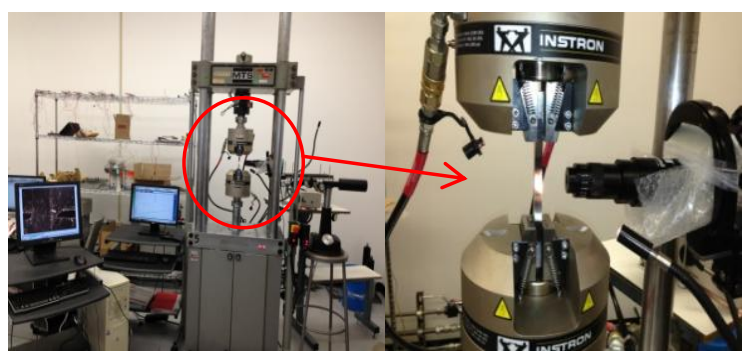

Figure 5: MTS machine load frame experimental layout along with the microscope installation and positioning relative to the test section

The start of each test was defined when the surface cracks had initiated and grown providing useful data. Similarly, the end of each test was defined as when no more useful data could be obtained. This happens when the surface cracks approaches the sample edge. However, the samples were fatigued until failure and completely broken to avoid breaking it in a brittle manner and affecting the fracture surface, which is the main source of elucidating crack growth data.

\subsection{Fractography measurements}

Both SEM fractography and optical microscopy were used to analyze the fracture surface of the failed samples. SEM was used to get a closer look at the marker bands and confirm their existence. A series of SEM fractography images are shown in Figure 6:
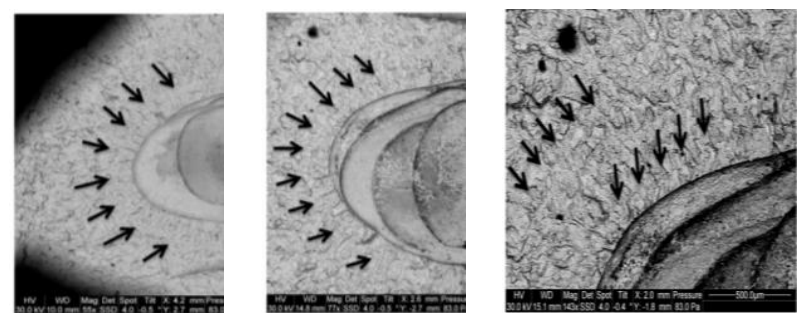

Figure 6: SEM images of the fracture surface that shows the marker bands

Although the SEM images show the marker bands clearly, optical microscopy yielded clearer fractography images that are easier for image processing. For that reason, optical microscopy was used as the standard method for fracture surface imaging.

The fatigue experiments provide two main sources of data:

1. Surface crack measurements at different number of cycles 


\section{Crack depth measurements, marker bands}

Relating the surface crack length to the crack depth at different number of cycles provided the data scatter required for the cracks growth modeling efforts. For identical cracks growth measurements, either of the two neighboring cracks could be measured for growth, as they propagate having a very similar growth rate. However, whenever there were two non-identical cracks, the bigger crack was monitored for growth, as it will be the dominating flaw as proven by the experimental work. A more detailed discussion of this process will be presented next.

Surface crack measurements were conducted using an optical microscope. The microscope continuously captured pictures of the sample surface during the fatigue experiment. This process was done in two main stages: before and after crack coalescence.

The microscope was focused on the area between the two cracks to take surface crack measurements before coalescence. Right at the point of coalescence, when the two surface crack tips touch, the microscope was moved to capture the surface crack growth on the other side of the notch towards the sample edge. In all experiments, the microscope was focused on the bigger crack. As the crack dimension affects the SIF around the crack tips and front, a faster crack growth rate was expected at the bigger crack.

After each experiment, high quality images were used for analysis and image processing. Each picture provided the number of cycles it took to achieve a certain crack growth. Moreover, these pictures were used to measure the surface crack growth, using an image-processing software called ImageJ. The software allowed for the correlation of the pixels of an image to the crack diameter or the sample width in order to find the surface crack length. This procedure allows finding the surface crack length at a specific number of cycles.

Other researchers like Leek and Howard (Leek \& Howard, An Examination of Methods of Assessing Interacting Surface Cracks by Comparison with Experimental Data, 1996) have used a traveling microscope to measure the surface crack length. Although traveling microscopes were widely used for such measurements, optical microscopy shows high levels of accuracy as image-processing software offers very high accuracy measurements.

Post-failure crack growth measurements were further conducted using quantitative fractography, which involved locating the marker bands on the failed sample fracture surface using an optical microscope. Marker bands similar to the ones conceptually illustrated in Figure 7 were located and used to measure the crack depth. Knowing the surface crack length and the associated number of cycles from the surface crack measurements, a correlated depth measurement could be made in order to find the crack depth at that surface crack length and number of cycles.

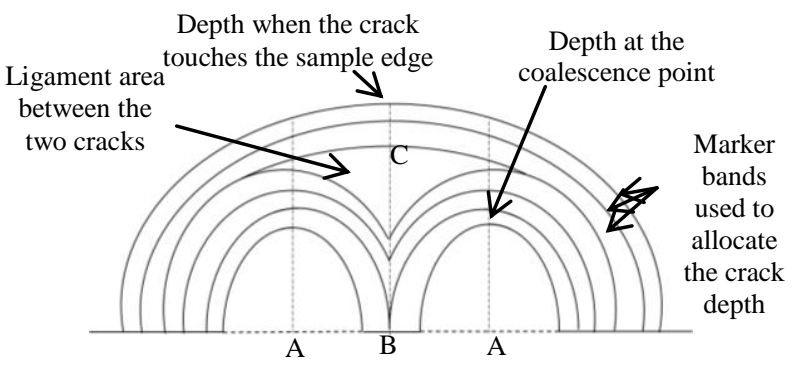

Figure 7: Marker bands illustration

The same image-processing software, ImageJ (i.e., a software developed by the National Institute of Health, USA), used for the surface crack measurements was used for the fracture surface analysis. The crack depth measurements were performed at the point of maximum depth of the bigger notch, A, points as illustrated in Figure 7 , until an enveloping crack is formed after coalescence. Then the depth measurements were made at the maximum depth of the enveloping crack, $\mathrm{C}$ points. This provided a realistic data scatter for the modeling development. For that reason, the crack center before coalescence is located at point A. However, the crack center shifts to point B right after coalescence to account for the bigger enveloping crack geometrical development.

\subsection{Experimental results}

As shown in Figure 8, the failed samples were cut and analyzed under the optical microscope; the fracture surface showed some marker bands that were used for the depth measurements. The fracture surface was then analyzed using Image $\mathrm{J}$, to find the crack depth.

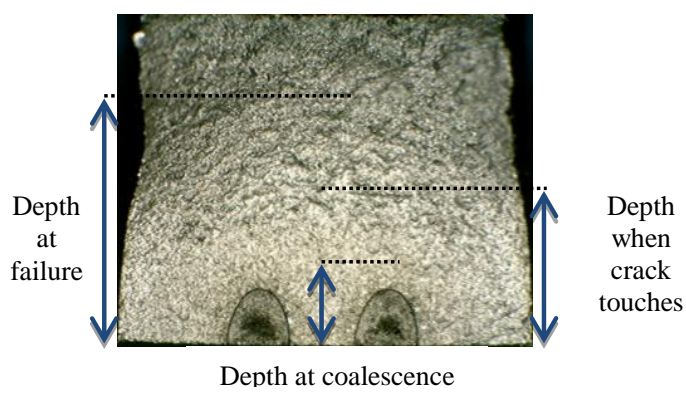

Figure 8: Crack depth Measurement using Image J software

One of the main variables in this work was the neighboring cracks dimensions. The main purpose of varying the cracks dimensions was to understand the impact of the crack dimensions variability on cracks coalescence and growth. Crack depth, diameter and spacing were varied and tested under the same loading conditions in order to define the impact of each dimension variable on the cracks growth. 
The first dimension tested was the neighboring cracks depth. Here, the cracks radius and spacing were kept constant. Moreover, all tests performed to examine the cracks dimensions were performed under the same loading conditions with a maximum stress of $290 \mathrm{MPa}$ and a loading ratio of 0.1 .

In order to understand the effect of the cracks depth variability, one of the cracks was kept at a constant depth of $1.6 \mathrm{~mm}$, while the other cracks' depth was varied. The bigger crack growth and development was monitored for the crack growth data generation and modeling purposes.

It was concluded that by increasing the depth of one of the neighboring cracks by one standard deviation (i.e., by $20 \%$ of the initial crack depth) we can accelerates failure by almost $23 \%$ as compared to the reference geometry (i.e., a_ $(\mu / \mu)$ having two identical cracks). Also, increasing the depth of one of the neighboring cracks by two standard deviations has a very similar failure time as compared to the one standard deviation depth increase case.

On the other hand, decreasing the depth of one of the neighboring cracks by one standard deviation, a_ $(\mu-\sigma / \mu)$, decelerates failure by nearly $10 \%$ compared to the reference geometry. Also, similarly decreasing the depth of the one of the neighboring cracks by two standard deviations yields very similar results to the one standard deviation depth decrease case. Figure 9 shows a summary of the findings by comparing the cycles to coalescence and cycles to failure amongst the different experiments discussed.

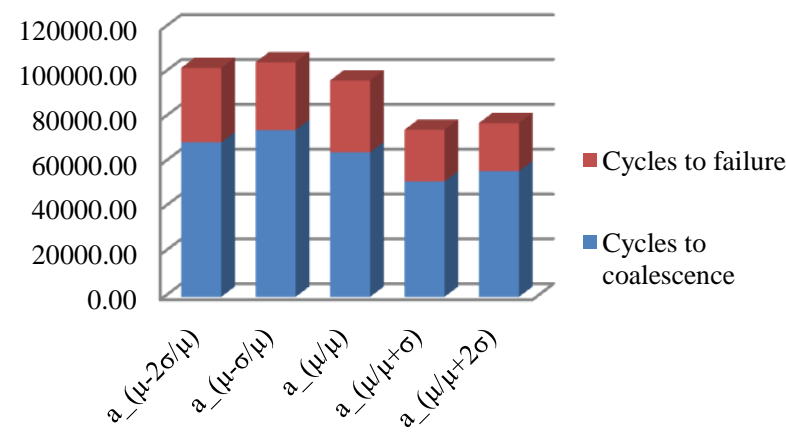

Figure 9: Impact of the neighboring cracks depth on the number of cycles to coalescence and failure

The crack depth measurements were plotted against different number of cycles in Figure 10 for a better understanding of the role of the initial cracks depth on the failure time.

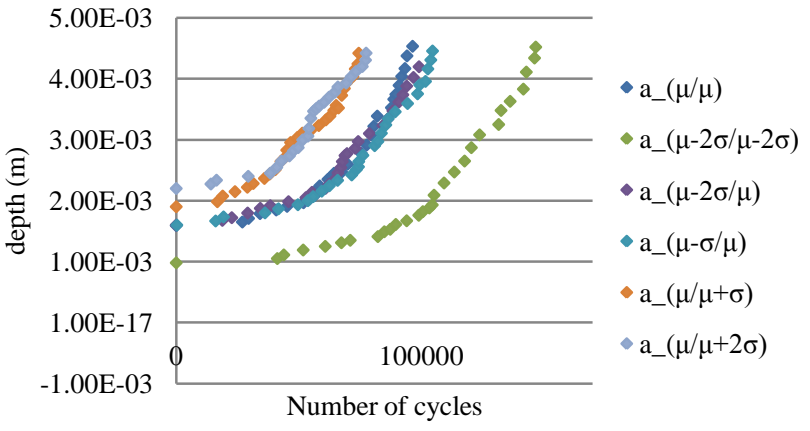

Figure 10: Plot of the number of cycles versus depth of neighboring crack of variable initial depth

Another dimension tested in this work was the cracks radius. In this part of the experimental work, the notches had a constant depth and spacing, however, one of the neighboring cracks radius was varied. It was found that decreasing the radius by either one or two standard deviations did not affect the sample failure significantly compared to the reference geometry.

According to Murakami et. al. (1981), spacing between neighboring cracks plays a major role in their interaction and coalescence. One of his major simulations conclusions is that if there is a space that allows the existence of a third crack between the two cracks, then the interaction effect between the two cracks at that specific geometric condition is negligible. This statement was investigated experimentally in this research as illustrated in Figure 11. A significant increase in the number of cycles to failure was observed when the two cracks were located further apart supporting Murakamis' conclusion.

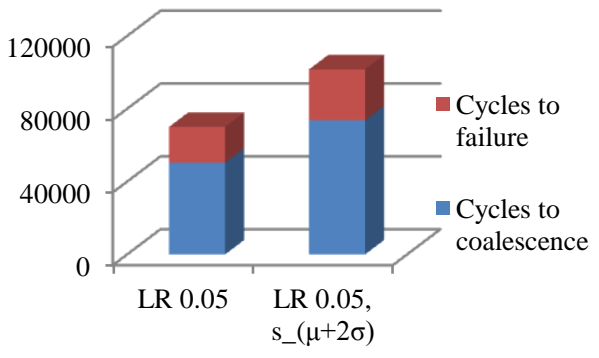

Figure 11: Increased neighboring cracks spacing effect on cycles to coalescence and failure

Moreover, two tests were performed with smaller spacing compared to the reference geometry in order investigate how that would accelerate failure. It was found that spacing has more influence on the number of cycles to achieve coalescence than it has on total cycles to failure. A main reason for this result is that by decreasing the distance between the two cracks, the distance between the outer crack tips and the sample edge increases. As the 
surface crack growth rate between the two cracks is much faster than it is at the outer crack tip, more time is needed to achieve total failure of the specimen which compensates for the time difference due to the faster time to coalescence caused by the smaller spacing.

As loading conditions play a major role in determining the life of engineering structures, different loading conditions were considered in this research. Applied stress and loading ratio are the two main loading variables considered. In this section of the experimental work, the geometry was kept constant and all tests were performed using the reference geometry a_ $(\mu / \mu)$.

In order to test the effect of stress on both times to coalescence and failure, the reference geometry was tested under a constant loading ratio of 0.1 at three different stresses. It was found that both times to coalescence and failure decrease by increasing stress.

On the other hand, In order to test the loading ratio effect on both times to coalescence failure, the reference geometry was tested under a constant stress of $290 \mathrm{MPa}$ and at three different loading ratios. It was perceived that both times to coalescence failure increased by increasing the loading ratio. For a more detailed discussion on the experimental results, see (Al Tamimi, 2014).

\section{SIF SimUlation WORK}

Performing a comprehensive simulation to find the SIF at the cracks tips is vital step in the model development in this work. Figure 12 shows the points where the SIF was calculated for the model developed in this research.

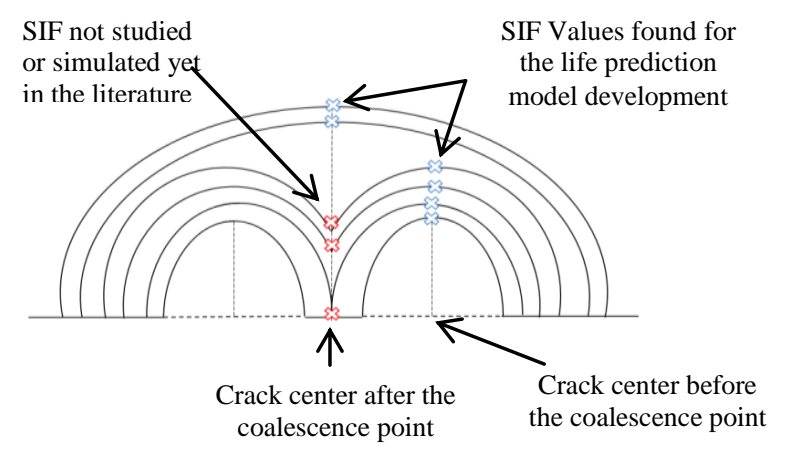

Figure 12: Specific geometrical points at which SIF was computed

\subsection{Crack front SIF simulation}

In order to find the SIF at the crack front, Newman and Raju (1981-1979) solutions of the SIF of a single semi-elliptical crack coupled with the CIF developed by Leek and Howard (1994) models were used. A discussion of this methodology is illustrated in this section.
Newman and Raju solutions (1979-1981) were used to develop a simulation routine that computes the crack front SIF, which covers a wide range of semi-elliptical crack dimensions. In order to find the SIF at the crack front, three main variables have to be defined before and after coalescence:

1. Crack depth at each increment of growth

2. Crack radius at each increment of growth

3. Loading conditions:

a) Maximum stress

b) Loading ratio

These variables are the main input variables to the crack front SIF equation beside other geometrical constants like the sample thickness and width. The input data were obtained from the experimental work performed in this research. So, for each crack development data set, the SIF was obtained for each increment of growth in order to develop a da/dn vs. $\Delta \mathrm{K}$ data scatter.

After obtaining the single crack SIF values at the crack front, it was corrected using Leek and Howard (1994) correction factor model based on the geometrical development of the cracks which was identified experimentally.

As Leek and Howard II (1994) method addresses identical cracks, an assumption was made in this research that in the cases of having two non-identical cracks, they are assumed to be identical and equal to the bigger crack for the SIF analysis. As shown earlier in the experimental results section in this work, it was found that increasing or decreasing the depth or the radius of one of the neighboring cracks by one or two standard deviations had a very mild impact on the total cycles to failure, for that reason, introducing this assumption will have acceptable accuracy when used for the SIF computation.

For each test, the SIF was obtained for a single crack and then corrected using the correction factors developed by Leek and Howard (1994). This method specifies geometrical conditions based on the cracks interaction and coalescence development providing a percentage increase in the SIF value anywhere around the crack. The corrected SIF value is then computed using equation (1).

The CIF shows the percent increase in the SIF value around a semi-elliptical crack when neighbored by another semielliptical crack at a certain geometrical condition. The crack front SIF was recalculated after each increment of growth until the two cracks touched. When the cracks were predicted to touch, a single enveloping crack was immediately assumed with new dimensions and a shift of the crack center to the coalescence point. When the enveloping crack was assumed, then Newman and Raju (1979-1981) solutions were used to continue computing the SIF at the enveloping crack front. 


\subsection{SIF simulation results}

In order to understand how neighboring cracks affect the SIF, a comparison was made between two cases: a SIF analysis assuming a negligible effect of neighboring cracks, and a second case that accounts for neighboring cracks interaction. This comparison is illustrated in Figure 13:

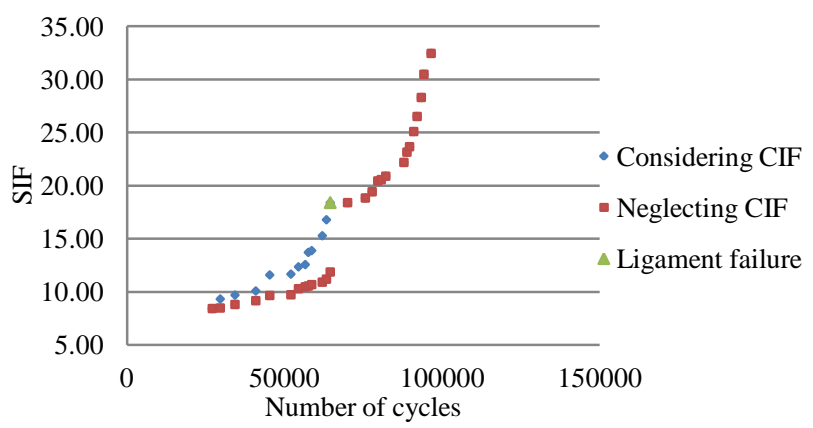

Figure 13: Plot of the number of cycles versus crack front SIF, an illustration of the impact of the CIF on SIF analysis, a_ $(\mu / \mu), \sigma \mathrm{s}=290 \mathrm{MPa}, \mathrm{LR}=0.1$

Neglecting the SIF correction factors leads to introducing a significant discontinuity in the SIF values introduced when the two cracks achieve coalescence forming a single enveloping crack. Neglecting the CIF provides misleading data about SIF actual development during the crack interaction and coalescence and provides no information about the ligament failure. Performing a proper SIF analysis provides useful information that explains how the two cracks interact and how the ligament between them fails.

From an inspection overview, the ease and applicability of the inspection, measurement and modeling method, side by side with the availability of the modeling tools needed to analyze different types of cracking in engineering structures defines a great portion of any crack growth prediction efforts. For that reason, when having any two initial nonidentical cracks, an assumption was made that the two cracks are of equal dimensions equivalent to the bigger crack. This will yield a simpler and easier to use life prediction model and will significantly simplify the SIF analysis performed.

The SIF variations due to changing the neighboring cracks dimensions were investigated in this work. The effect of changing one of the neighboring cracks depth, radius and the spacing between the two cracks on SIF was observed and discussed.

Compared to the reference geometry, increasing one of the neighboring crack depths by one or two standard deviations did not introduce major change in the SIF values. A very similar trend of SIF was observed when compared to the experimental results. The same trend was also observed by decreasing one of the neighboring cracks depths by one or two standard deviations. However, the SIF was increasing with a slower rate as illustrated in Figure 14.

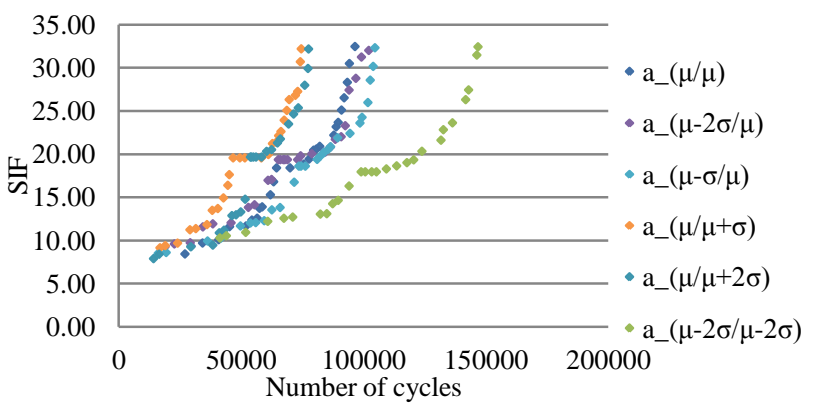

Figure 14: Plot of the number of cycles versus crack front SIF of neighboring cracks of variable initial depth

When cracks coalescence is achieved, a change is in the SIF development behavior is observed. The reason for that is the actual ligament failure when the two surface cracks coalesce and one bigger enveloping crack is formed. This sudden increase in the crack dimension causes a rapid increase in the SIF value.

As changing one of the neighboring crack radiuses by one or two standard deviations did not affect crack growth in the experimental results significantly, the impact of changing the radius was neglected in the SIF analysis and the two cracks were assumed to be identical. When the three different experiments testing the radius impact on cracks coalescence were compared and analyzed, a very similar trend of the ligament failure was observed and was identified to happen right before the coalescence point.

As the spacing between the two cracks plays a major role in defining the number of cycles to coalescence, a very similar effect on the SIF development was observed. Faster coalescence means a faster failure of the ligament between the two cracks and a faster formation of the enveloping crack. The only difference between the three cases is when coalescence is achieved leading to a change in the SIF growth behavior.

Loading conditions have a direct impact on the SIF computation, for that reason, different applied stress levels and the associated loading ratios were considered in this work. The SIF have a very similar development behavior at different stresses before and after coalescence except that increasing the stress accelerates failure.

Also, changing the loading ratio at a given stress level has a noticeable impact on the crack growth rate as it affects the applied stress levels directly. For that reason, the impact of the loading ratio on the SIF values was investigated and was found to have a similar behavior to the different stress levels impact on SIF.

Finally, the ligament failure was observed to follow a very similar trend to the previous experiments. Ligament failure 
occurred right before the coalescence point leading to this change in SIF development behavior.

\subsection{Ligament failure simulation results}

In the simulation efforts performed in this research, the ligament failure between the two cracks was investigated. As Leek and Howard II (1994) method was used for correcting the SIF in order to account for the neighboring cracks effect, yet, this method addresses identical cracks only. An assumption was made in the cases of two nonidentical cracks that they are assumed to be identical and equal to the bigger crack. For that reason, the ligament failure investigation performed in this research only addresses identical crack as this assumption will directly affect any conclusions about the ligament failure in such geometries.

According to Leek and Howard (1994), as the two cracks approach each other; the CIF values increase rapidly. So, there will always be a certain dimensional criterion at which the maximum SIF obtained by the use of the CIF method becomes larger than that obtained by assuming an enveloping crack. That specific point is assumed to be the point at which ligament failure occurs. However, in reality, many factors affect number of cycles to ligament failure. The type of material, material microstructure, loading conditions and the crack sizes are some of the obvious factors affecting the ligament failure.

The impact of the loading conditions on the time to ligament failure was investigated in this research. Based on the SIF simulations performed, the number of cycles to achieve ligament failure was obtained for each test. Afterwards, it was compared to the overall cycles to failure. It was found that Higher applied stress levels and higher loading ratios had the same accelerating impact on ligament failure. Both applied stress and the loading ratio were correlated to number of cycles to ligament failure by a linear function due to the linear increase in the SIF values at the neighboring cracks fronts. This is illustrated in Figure 15 and Figure 16:

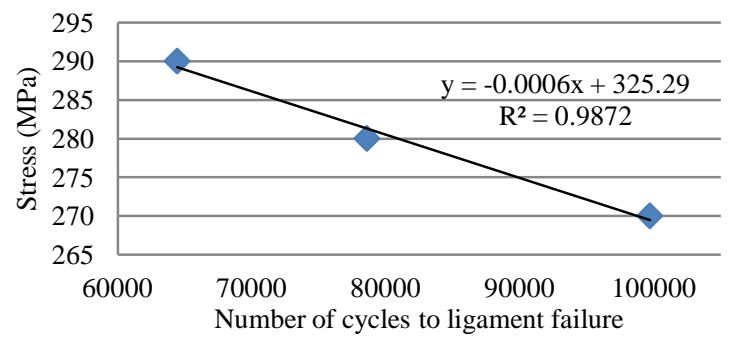

Figure 15: Plot of number of cycles to ligament failure versus applied stress

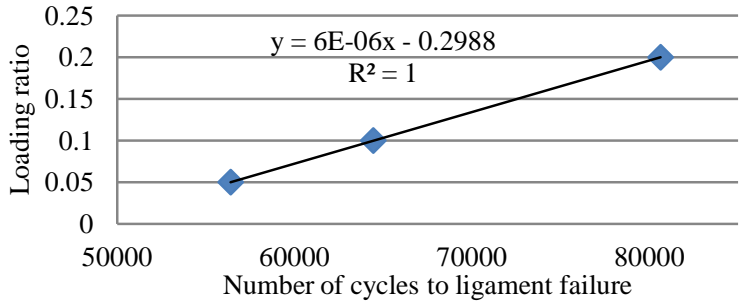

Figure 16: Plot of number of cycles to ligament failure versus loading ratio

Additional simulations and experimental work are needed in order to understand and justify such failures of the ligament. For a more detailed discussion on the SIF simulation results, refer to (Al Tamimi, 2014).

\section{MODEL DEVELOPMENT}

After discussing data gathering and characterizing data scatter development, a realistic modeling technique is required. This section covers the probabilistic crack growth modeling approach followed in this paper. The proposed model incorporates experimental and simulation results for a better understanding of the cracks interaction and coalescence and its impact on the fatigue life of engineering structures.

\subsection{Modeling Assumptions}

This section presents the foremost assumptions employed in developing the life prediction model. Some of the assumptions were made based on the SIF analysis performed in this research, while others were made based on the nature of the experimental and modeling efforts performed. These assumptions are not expected to significantly affect the results of the data scatter established nor the developed model outcomes. However, uncertainties due to these assumptions were not quantified. The following is a list of the assumptions used in this work:

- Cracks will grow keeping their semi-elliptical shape

- When the inner tips of the neighboring cracks touch, a single enveloping semi-elliptical crack is formed due to the rapid ligament failure

- Non-identical cracks are assumed to be identical and equal to the bigger crack

- Whenever there are two non-identical cracks, the bigger cracks is monitored for crack growth as it will be the dominating flaw as proven by the experimental work

- The material is assumed to be homogeneous and isotropic

\subsection{Crack Growth Model}

The crack growth rate model considered in this work was based on the Walker equation. The ease of use, simplicity, 
wide acceptance in the literature and reasonable number of parameters were the main criteria behind selecting this model. A summary of the models inputs, output and mathematical representation is summarized in Table 2:

Table 2: A summary of the PoF models used in this research, inputs, outputs and mathematical representation

\begin{tabular}{|c|c|}
\hline Model inputs & $\begin{array}{c}\text { Stress Intensity Factor }(\Delta \mathrm{K})^{1} \\
\text { Loading ratio }\end{array}$ \\
\hline Model output & Crack growth rate $(\mathrm{da} / \mathrm{dN})$ \\
\hline Mathematical representation & $\frac{d a}{d N}=f(\Delta \mathrm{K}, L R \mid C, n, \lambda)$ \\
\hline Equation & $\frac{\mathrm{da}}{\mathrm{dN}}=\frac{\mathrm{C}(\Delta \mathrm{K})^{\mathrm{n}}}{(1-\mathrm{LR})^{\mathrm{n}(1-\lambda)}}$ \\
\hline
\end{tabular}

The Walker model has three main uncertain parameters $(C$, $\mathrm{n}, \lambda$ ). An extensive literature survey was performed to gather prior information about each parameter used in the modeling development efforts. Many researchers have investigated crack growth in carbon steel materials due to its widespread use in engineering structures. For that reason, various Paris law coefficients are available in the literature. Some of these values were used in this research to develop prior distributions for these coefficients.

This data obtained from the literature was used to estimate the best distribution that fits the data. It was found that the normal distribution best fits the data of both coefficients.

Similarly, the Walker model has one uncertain parameter, $\lambda$, which correlates the loading ratio variable with the crack growth rate. (Dowling, Calhoun, \& Arcari, 2008) have investigated this parameter for different grades of steel. These values were used to develop a prior distribution of the parameter $\lambda$. It was found that the normal distribution was found to best fit the data.

\subsection{Evidence Data Handling}

This section discusses how the data scatter developed in this research will be employed in the modeling technique. Two main steps are required to develop the PoF crack growth rate model as illustrated in Figure 17:

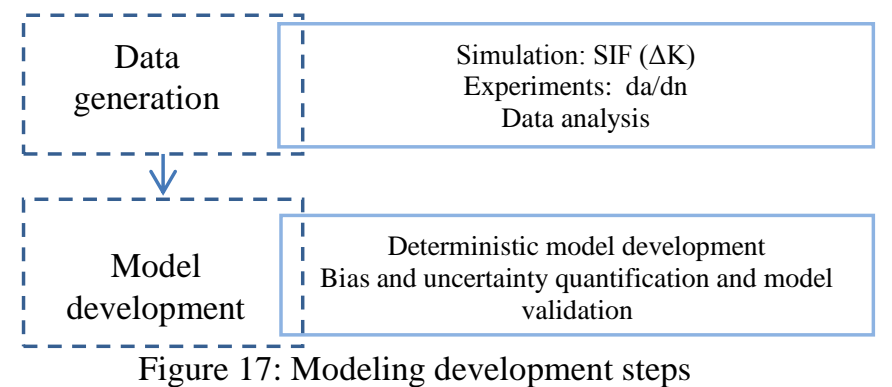

${ }^{1}$ Corrected for the impact of neighboring cracks using the CIF
The data scatter developed in this work has been split into two main sets:

1. Deterministic model development data set

2. Bias and uncertainty quantification and model validation data set

Each model development stage requires an independent data in order to avoid or minimize the bias and avoids overlapping results. The first set of data was used to update the model uncertain parameters distributions. On the other hand, the second set of data was used to quantify the uncertainty and validate the proposed model.

\subsection{Deterministic Model Development}

As deliberated earlier, the modeling efforts discussed developing a PoF crack growth rate model based on the Walker equation. A mathematical representation of the model is illustrated in equation (3):

$$
\frac{d a}{d n}=f(\Delta K, R \mid \mathrm{C}, \mathrm{n}, \lambda)
$$

In order to shape the final form of the deterministic model, a proper evaluation of the model uncertain parameters is required. The proposed model parameters $\mathrm{C}, \mathrm{n}$ and $\lambda$ have been estimated using generic data available in literature, experiments and simulations developed in this research.

As there are many possible fatigue experiments and simulations to perform to fully understand the nature of interactions between neighboring cracks, obtaining data for such failure mechanism has proven to be difficult, time consuming and very expensive. A useful analytical method that enables the integration of new evidence with the existing prior knowledge and produces an updated knowledge of the uncertain model parameters is Bayes' theorem. As such, the Bayesian inference method was applied to estimate the uncertain parameters $\mathrm{C}, \mathrm{n}$ and $\lambda$. A summary of the Bayesian approach used is illustrated in Figure 18:

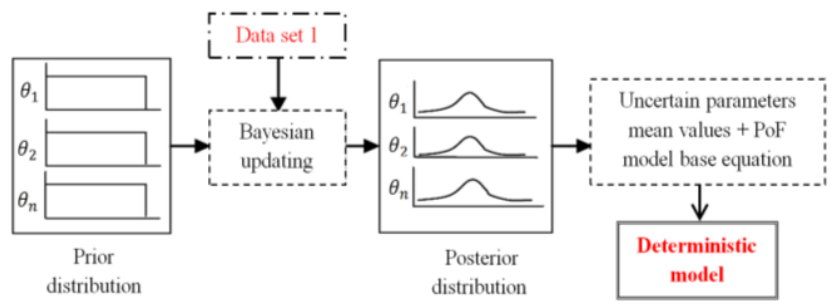

Figure 18: Deterministic model development (Azarkhail \& Modarres, 2012)

The prior joint probability distribution of the model uncertain parameters $f_{o}(C, n, \lambda)$ was defined. Subsequently, this prior was combined with the evidence data (obtained from our experiments) in the form of a likelihood function. The likelihood equation of the crack growth rate was 
assumed to follow a normal distribution and is illustrated in equation (4):

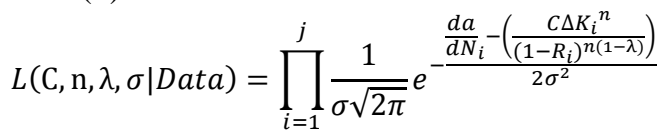

The result is an updated state of knowledge identified as the posterior distribution, $\mathrm{f}(\mathrm{C}, \mathrm{n}, \lambda, \sigma \mid$ Data $)$. This process is shown mathematically in equation (5):

$$
f(\mathrm{C}, \mathrm{n}, \lambda, \sigma \mid \text { Data })=\frac{L(\mathrm{C}, \mathrm{n}, \lambda \mid \text { Data }) f_{0}(\mathrm{C}, \mathrm{n}, \lambda)}{\int_{\theta} L(\mathrm{C}, \mathrm{n}, \lambda \mid \text { Data }) f_{0}(\mathrm{C}, \mathrm{n}, \lambda)}
$$

To accomplish this task, WinBUGS software program was employed to run the Bayesian analysis. In line with (Spiegelhalter, Thomas, Best, \& Lunn, 2003) the WinBUGS program is a windows-based environment for MCMC simulation. A wide variety of modeling applications could benefit from using such software.
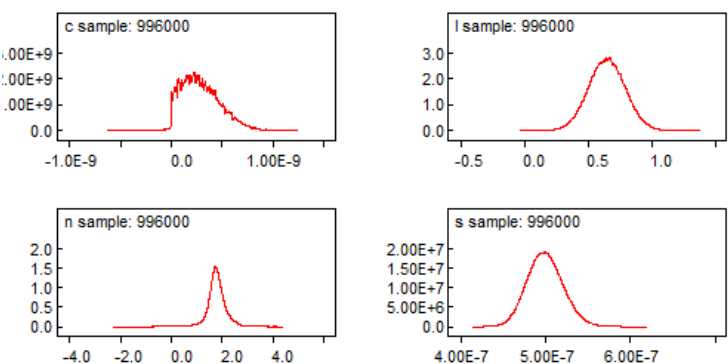

Figure 19: Walker model uncertain parameters $C, n$ and $\lambda$ posterior distributions

Table 3 shows the final results of the Bayesian updating process of the model parameters.

Table 3: $\mathrm{C}, \mathrm{n}, \lambda$ and $\sigma$ posterior distributions as calculated in WinBUGS for 200000 samples

\begin{tabular}{|c|c|c|c|c|c|}
\hline node & $\mu$ & $\sigma$ & $2.50 \%$ & median & $97.50 \%$ \\
\hline $\mathrm{C}$ & $2.88 \mathrm{E}-10$ & $2.14 \mathrm{E}-10$ & $8.52 \mathrm{E}-12$ & $2.64 \mathrm{E}-10$ & $7.07 \mathrm{E}-10$ \\
\hline $\mathrm{n}$ & 1.785 & 0.39 & 0.9817 & 1.773 & 2.588 \\
\hline$\lambda$ & 0.6473 & 0.143 & 0.3672 & 0.6471 & 0.9293 \\
\hline $\mathrm{s}$ & $4.99 \mathrm{E}-07$ & $2.09 \mathrm{E}-08$ & $4.60 \mathrm{E}-07$ & $4.99 \mathrm{E}-07$ & $5.42 \mathrm{E}-07$ \\
\hline
\end{tabular}

After developing the knowledge of the model parameters distributions, a family of models could be developed and assessed in order to find the model with least uncertainty. This was done by dividing each parameters' marginal distribution into three equally probable regions and find the median of each region. Then, the different combinations of these median values yielded the different model families shown in Figure 20:

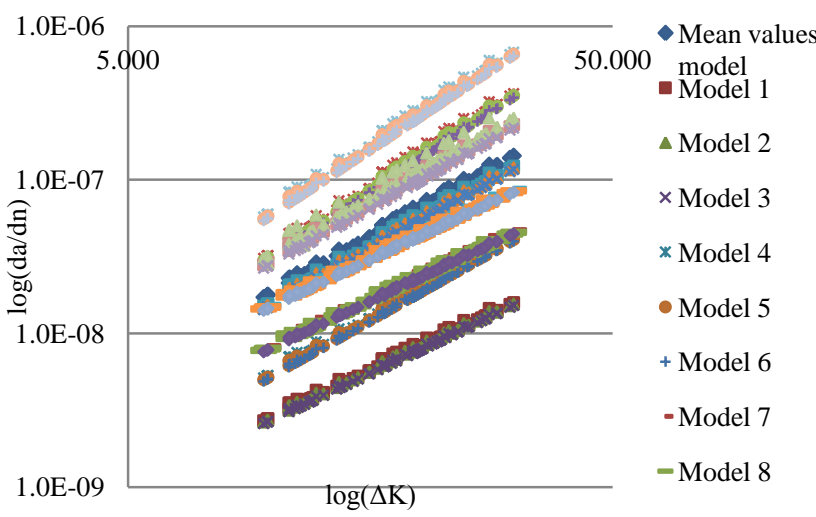

Figure 20: Families of the Walker model describing crack growth rate of neighboring cracks

The uncertain parameters correlations were also obtained using WinBUGS, however, no correlations were found as illustrated in Figure 21:
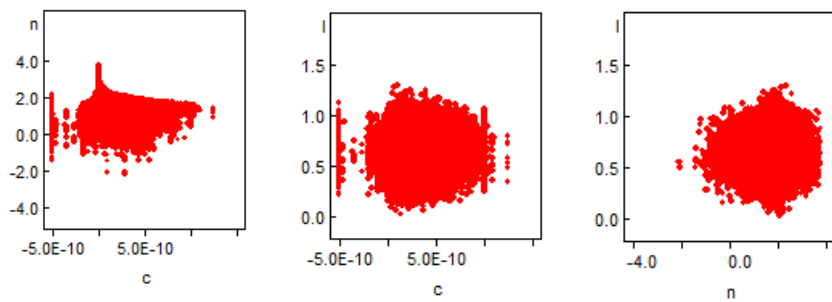

Figure 21: Walker equation model uncertain parameters correlations as calculated in WinBUGS for 200000 samples

\section{MOdel BIAS AND UnCERTAINTY QUANTIFICATION}

\subsection{Sources of Experimental Data Uncertainty}

One of the main aims of identifying sources of uncertainty in any research is to recognize the weakness of certain apparatus, experimental layout, simulation technique or even the model development process. Also, identifying the uncertainties of specific data gathering technique makes the modeling output more reliable.

Two key sources of uncertainties in this research were investigated: stochastic and systematic uncertainties associated with the experimental measurements and epistemic uncertainties associated with the models predictions.

Figure 22 shows a summary of sources of uncertainty addressed in this work along with a classification based on the two categories of uncertainties mentioned. For a more general discussion on the different sources of uncertainty, refer to (Keshtgar \& Modarres, 2013) 


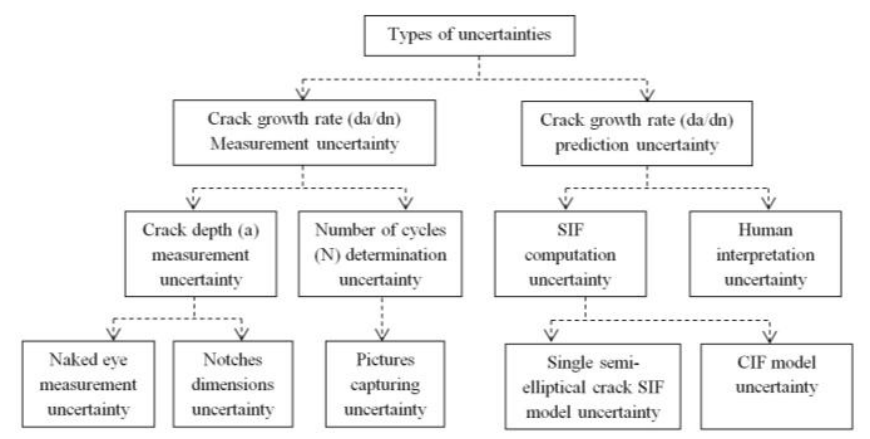

Figure 22: Experimental measurement and model prediction uncertainties breakdown

Each category will be addressed separately for an understanding of the nature of the uncertainties affecting it, and quantified using an appropriate uncertainty quantification technique.

\subsection{Sources of Experimental Data Uncertainty}

The first source of uncertainty in the crack depth measurement is the test samples fabrication. The test specimens were manufactured using a laser-cutting technique that yields high precision measurements and minimum residual stresses. Furthermore, the samples were made by one person in order to reduce uncertainty in the samples dimensions. Moreover, the samples were made using the same batch of API-5L grade B carbon steel in order to avoid any variation in the material properties across the testing samples. However, inducing the initial notches using the EDM technique had some uncertainty, which was addressed in this work. As confirmed by the machine shop, which performed the EDM notching, the dimensions of the initial notches have an uncertainty of $\pm 0.1 \mathrm{~mm}$. As this kind of uncertainty is defined by the manufacturer, no further quantifications are required.

The second source of uncertainty is the actual crack depth measurements. All crack measurements were analyzed using image-processing software, however, the measurements were performed with the naked eye, for that reason, each measurement was performed twice at two different times to reduce both bias and uncertainty of the measurements.

Performing each measurement twice enabled quantifying the uncertainty associated with the naked eye measurement. A sizing error model (i.e. a model that addresses the correlation between the crack size and the measurement uncertainty) was used in order to quantify the naked eye measurement uncertainty as illustrated in equation (6):

$$
\Delta_{\varepsilon}=m_{\varepsilon}\left(P_{\text {avg }}\right)+b_{\varepsilon}
$$

A Bayesian inference was used to obtain the model parameters, $m_{\varepsilon}$ and $b_{\varepsilon}$. A subjective uniform prior of the model uncertain parameters was introduced. Subsequently, this prior was combined with the experimental data in the form of a normal likelihood function.

The result of the Bayesian inference is an updated state of knowledge identified as the posterior distribution of the sizing error model parameters $m_{\varepsilon}$ and $b_{\varepsilon}$. To accomplish this task, WinBUGS software program was employed to run the Bayesian analysis. After running the developed WinBUGS code, a posterior knowledge of the uncertain parameters $m_{\varepsilon}$ and $b_{\varepsilon}$ along with the model standard deviation was obtained as illustrated in Table 4:

Table $4: \mathrm{m}_{\varepsilon}, \mathrm{b}_{\varepsilon}$ and $\sigma$ posterior distributions as calculated in WinBUGS for 50000 samples

\begin{tabular}{|c|c|c|c|c|c|}
\hline node & $\mathrm{M}$ & $\Sigma$ & $2.50 \%$ & median & $97.50 \%$ \\
\hline $\mathrm{b}$ & 0.76 & 0.14 & 0.005 & 0.48 & 0.77 \\
\hline $\mathrm{m}$ & 0.0026 & $9.35 \mathrm{E}-04$ & $3.21 \mathrm{E}-05$ & $7.92 \mathrm{E}-04$ & $2.58 \mathrm{E}-03$ \\
\hline $\mathrm{s}$ & 0.61 & 0.03 & $1.53 \mathrm{E}-04$ & $5.55 \mathrm{E}-01$ & 0.61 \\
\hline
\end{tabular}

As shown in Table 4, the parameter $m_{\varepsilon}$ has a mean value of 0.002589 that indicates a mild correlation between the duplicated measurements average and the associated difference between them. The difference between each of the duplicated measurements was then converted into a percentage as a first step of the uncertainty quantification. Subsequently, the overall naked eye measurement uncertainty was obtained by computing the root sum squares of these percentage values. So the standard overall naked eye measurement uncertainty was found to be almost $16 \%$.

Other sources of experimental uncertainties were also present in this work; such as test repeatability and sample size uncertainties. However, it doesn't affect the crack measurements or the associated number of cycles determination directly. Yet, it was addressed for the sake of completion and covering all different possible sources of uncertainty.

Four experiments were duplicated (i.e., two identical cracks geometry $\left(\mathrm{a} \_(\mu / \mu)\right)$, two non-identical cracks geometry a_ $(\mu / \mu+\sigma)$, LR test $(\mathrm{LR}=0.05)$ and applied stress test $\left.\left(\sigma_{\mathrm{s}}=280 \mathrm{MPa}\right)\right)$ in order to confirm the results obtained and assure the consistency of measurements. The repeated tests were a representative sample of the overall experiments performed in this research as two tests address the impact of neighboring cracks geometry, one test addresses the impact of the loading ratio and one test addresses the impact of the applied load on the crack growth rate. The form was repeating the same test under the same loading conditions for the same notches geometry and dimensions using two different samples. However, in order to quantify such uncertainty, more duplicated tests are required to provide a data scatter.

Also, it is important to mention that each test provided a different number of measurements based on the quality of 
the fractography images provided by the camera. For that reason, the sample size uncertainty was also taken into consideration. Accordingly, a mean value of the experiments resulting measurements sample sizes was obtained along with a standard deviation (i.e. measurements sample size uncertainty). The samples size uncertainty was found to be $16.74 \%$.

\subsection{Sources of Model Predictions Uncertainties}

In this step, a more comprehensive model bias and uncertainty analysis is performed. A method developed by Azarkhail and Modarres (2007) and Ontiveros, Cartillier and Modarres (2010) and modified and used later by Keshtgar (2014) to quantify the model uncertainties will be used. However, a different set of evidence data is used for this purpose. The bias and uncertainty quantification is based on comparing the model predictions with the experimental results as illustrated in Figure 23:

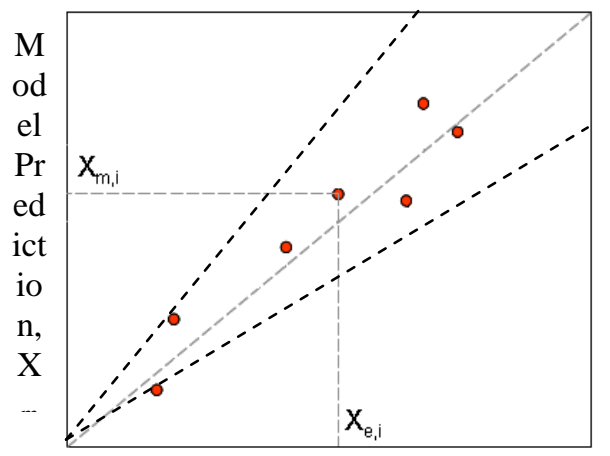

Experimental Result, $\mathrm{X}_{\mathrm{e}}$

Figure 23. Deterministic model predictions compared to experimental results (Azarkhail, Ontiveros, \& Modarres, 2009)

If the model predictions perfectly matched the experimental results, then all the points would lie exactly on the dotted line which is not highly probable. This is because of the uncertainties and possible bias in both the model predictions and the experimental measurements.

In this research, the model prediction and experimental result are considered to be estimations of the crack growth rate $(\mathrm{da} / \mathrm{dN})$, given some error as shown in equations (7) and (8):

$$
\begin{gathered}
\frac{d a / d N_{i}}{d a / d N_{e, i}}=F_{e, i} ; F_{e} \sim \operatorname{LN}\left(b_{e}, s_{e}\right) \\
\frac{d a / d N_{i}}{d a / d N_{m, i}}=F_{m, i} ; F_{m} \sim \operatorname{LN}\left(b_{m}, s_{m}\right)
\end{gathered}
$$

As the modeling addresses crack growth values, then the model outcome is always expected to be a positive value, for that reason, a multiplicative error model is assumed.
Moreover, the error is assumed to be distributed lognormally for the same reason.

As the true value of the crack growth rate $d a / d N_{i}$ is unknown, equations (7) and (8) are combined yielding the following equations:

$$
\begin{gathered}
F_{e, i}\left(d a / d N_{e, i}\right)=F_{m, i}\left(d a / d N_{m, i}\right) \\
\frac{d a / d N_{e, i}}{d a / d N_{m, i}}=\frac{F_{m, i}}{F_{e, i}}=F_{t, i}
\end{gathered}
$$

Assuming independency of $F_{m}, F_{e}$ then:

$$
F_{t} \sim L N\left(b_{m}-b_{e}, \sqrt{s_{m}^{2}+s_{e}^{2}}\right)
$$

The likelihood used in the Bayesian inference is illustrated in equation (12):

$$
\begin{aligned}
& L\left(F_{t, i}, b_{e}, s_{e} \mid b_{m}, s_{m}\right) \\
& =\prod_{i=1}^{n} \frac{1}{\sqrt{2 \pi}\left(F_{t, i}\right) \sqrt{s_{m}^{2}+s_{m}^{2}}} e^{-\frac{\left[\ln \left(F_{t, i}\right)-\left(b_{m}-b_{e}\right)\right]^{2}}{2\left(s_{m}{ }^{2}+s_{m}{ }^{2}\right.}}
\end{aligned}
$$

Finally, the Bayesian inference is performed, where equation (13) shows the relation between the posterior distribution of the model parameter with the likelihood function and the prior evidence.

$$
\begin{gathered}
f\left(b_{m}, s_{m} \mid F_{t, i}, b_{e}, s_{e}\right) \\
=\frac{L\left(F_{t, i}, b_{e}, s_{e} \mid b_{m}, s_{m}\right) f_{0}\left(b_{m}, s_{m}\right)}{\int\left(L\left(F_{t, i}, b_{e}, s_{e} \mid b_{m}, s_{m}\right) f_{0}\left(b_{m}, s_{m}\right)\right)}
\end{gathered}
$$

The data used in this step of the analysis must be data independent of the data used in the model development step.

Quantifying the bias and uncertainty is considered also a validation of the models proposed. Assuming the modelbased predicted crack growth rate is $\mathrm{da} / \mathrm{dn}_{\mathrm{m}}$, the true crack growth rate prediction can be estimated by multiplying $\mathrm{da} / \mathrm{dn}_{\mathrm{m}}$ by the estimated $\mathrm{F}_{\mathrm{m}}$ :

$$
{\frac{d a}{d N_{\text {true }}}}=\frac{d a}{d N_{m}} \cdot F_{m}
$$

The model prediction results will be modified using the resulted bias distribution which can be estimated by a lognormal distribution:

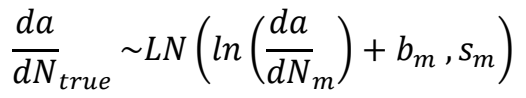

The mean Walker model (i.e., developed using the mean values of the uncertain parameters posterior distributions) multiplicative error was computed. A summary of the resultant statistics is illustrated in Table 5: 
Table 5: Walker model uncertainty quantification and validation summary

\begin{tabular}{|c|c|c|c|c|c|}
\hline node & $\mu$ & $\sigma$ & $2.50 \%$ & median & $97.50 \%$ \\
\hline $\mathrm{F}_{\mathrm{m}}$ & 0.8482 & 0.4786 & 0.259 & 0.742 & 2.06 \\
\hline $\mathrm{b}_{\mathrm{m}}$ & -0.3014 & 0.05883 & -0.420 & -0.301 & -0.187 \\
\hline $\mathrm{s}_{\mathrm{m}}$ & 0.5268 & 0.04248 & 0.451 & 0.524 & 0.616 \\
\hline
\end{tabular}

The model uncertainty bounds for the crack growth rate can be determined from the percentiles of $\mathrm{F}_{\mathrm{m}}$. So, the resulting uncertainty upper bound is $106 \%$ while the low bound is $74 \%$. In other words, a model user could be $95 \%$ confident that the true value resides between $106 \%$ higher and $74 \%$ lower than what the model predicts. This is shown graphically in Figure 24:

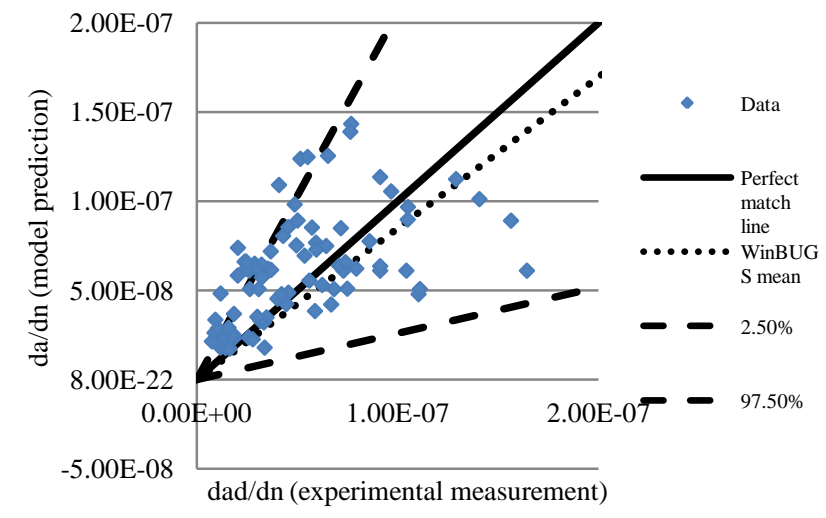

Figure 24: Walker equation posterior predictive model with the uncertainty bounds

When observing the mean value of $F_{m}$, the model shows a bias of $15 \%$, under-estimating the true value of the crack growth rate. Also, it has a wide range of uncertainty. A considerable portion of the model uncertainty comes from the SIF computation, data scatter and the form of the model used.

However, other models were also investigated in order to come up with a model that offers slight conservatism with acceptable bias and uncertainty. A different model, as illustrated in equation (16), was found to provide more conservative predictions with less bias, however, it yielded a slight increase in uncertainty.

$$
\frac{\mathrm{da}}{\mathrm{dN}}=\frac{(2.54 \mathrm{E}-10)(\Delta \mathrm{K})^{1.769}}{(1-\mathrm{R})^{0.648}}
$$

This model provides $95 \%$ confidence that the true value of crack growth rate resides between 146\% higher and 69\% lower than what the model predicts. As the uncertainty increases for this model prediction, yet, less bias (i.e, $1 \%$ over-predicting the true crack growth rate) and a slight conservatism are observed.

\subsection{Walker Model Uncertainty Treatment}

The Walker model was further treated in order to minimize its uncertainty. One way to have a better crack growth rate predictions with reasonable uncertainty is by splitting the model into two main sub-models; the first representing the crack growth rate before coalescence and the second representing it after coalescence as illustrated in Figure 25. However, more work has to be done in order to define the coalescence point were the ligament failure occurs as accurately as possible. It is vital to do more experimental and simulation investigations to be able to come up with a time to ligament failure model which will define the threshold between the two crack growth rate models.

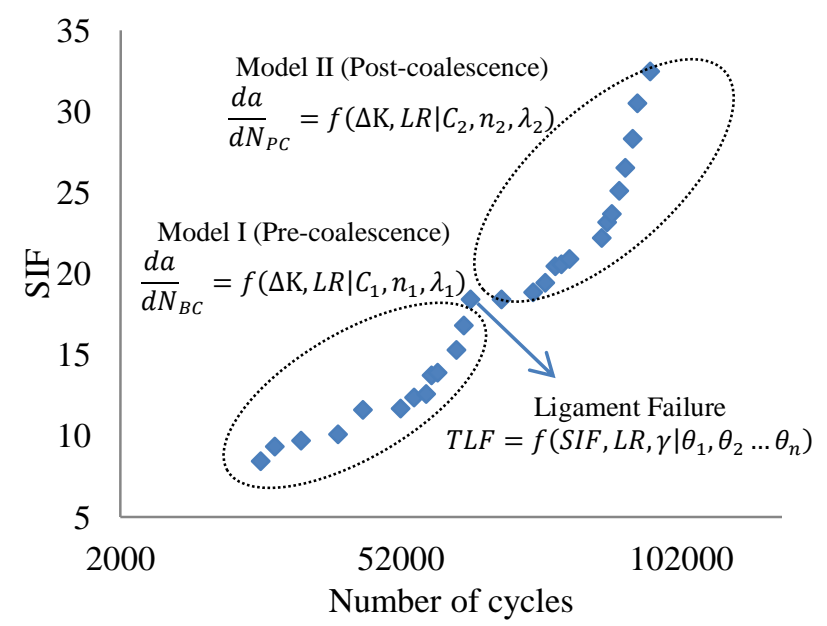

Figure 25: A strategy to model crack growth rate at different stages of crack interaction

Even though more data is required for applying such modeling strategy, some work was done in this direction in order to illustrate how such crack growth rate modeling strategy would minimize predictions uncertainties. It was possible in this work to show how splitting the crack growth rate model into two sub-models (i.e. pre-coalescence model and post-coalescence model) minimizes uncertainty; however, the data available was not enough to come up with a time to ligament failure model.

\subsubsection{Pre-coalescence crack growth rate model}

The first step of developing the pre-coalescence Walker model is the Bayesian inference. The same subjective prior pdf of each of the model uncertain parameters $\mathrm{f}_{\mathrm{o}}(\mathrm{C}, \mathrm{n}, \mathrm{m})$ used earlier was used herein. Subsequently, this prior was combined with the crack growth rate experimental data and the crack tip SIF simulation data before coalescence in the form of a normal distribution likelihood function as illustrated earlier in equation (12). The result is an updated state of knowledge identified as the posterior distribution, $\mathrm{f}(\mathrm{C}, \mathrm{n}, \mathrm{m}, \sigma \mid$ Data). This process was shown earlier mathematically in equation (13). 
The mean values of each uncertain parameter distribution were used in order to develop the pre-coalescence crack growth model and quantify its bias and uncertainty as illustrated in equation (17):

$$
\frac{\mathrm{da}}{\mathrm{dN}}=\frac{(2.29 \mathrm{E}-10)(\Delta \mathrm{K})^{1.85}}{(1-\mathrm{R})^{0.653}}
$$

When observing the mean value of $\mathrm{F}_{\mathrm{m}}$, the model shows a bias of less than $10 \%$ compared to $15 \%$ when not considering this distinction between the two phases of neighboring cracks growth (i.e. before coalescence and after coalescence). Also, this model shows similar uncertainty when compared to the Walker model even though the data sets used for the model development and validation are much smaller than those used for developing the mean Walker model. So, it is likely that using more data to develop and validate the pre-coalescence Walker model will yield less bias and uncertainty.

\subsubsection{Post-coalescence crack growth rate model}

Following the same procedure used earlier for developing the pre-coalescence Walker model, a posterior knowledge of the uncertain parameters $\mathrm{C}, \mathrm{n}$ and $\lambda$ was obtained for the post-coalescence Walker model as illustrated in equation (18):

$$
\frac{\mathrm{da}}{\mathrm{dN}}=\frac{(2.29 \mathrm{E}-10)(\Delta \mathrm{K})^{1.85}}{(1-\mathrm{R})^{0.653}}
$$

When observing the mean value of $\mathrm{F}_{\mathrm{m}}$, the post-coalescence model shows slightly higher bias (i.e. 20\%) compared to $15 \%$ in the mean Walker model. However, this model shows a significant lesser uncertainty when compared with the mean Walker model even though the data sets used for the model development and validation are much smaller than those used for developing the mean Walker model. So, it is likely that using more data to develop and validate the postcoalescence Walker model will yield less bias and uncertainty.

When comparing the two modeling strategies (i.e., modeling crack growth rate before and after coalescence in one model versus modeling the crack growth rate before coalescence in one model and after coalescence in a different model) it was found that the two models strategy is more promising. For a more detailed discussion on the modeling work, uncertainty quantification and validation, refer to (Al Tamimi, 2014).

\section{CONCLUSION}

This paper developed a new and improved experimental layout and procedure to investigate cracks interaction, coalescence and growth in carbon steel materials. A reliable design of experiment based on improving crack monitoring techniques available in the literature was presented. This was done through the use of real-time microscopy to monitor the cracks during the interaction and coalescence process, which increased the measurements accuracy. The fractography images were processed using image processing software to obtain the most accurate measurements possible and assure the consistency throughout the different tests. Moreover, an approach was devised in order to monitor the cracks coalescence and growth stages by correlating the surface crack growth with the crack front growth using different microscopy tools and image processing.

The paper presented a more realistic understanding of the effects of neighboring cracks and the dimensional variability on their interaction, coalescence and growth process. It was that increasing the depth of one of the neighboring cracks by one standard deviation accelerates failure by almost $23 \%$. Also, it was found that increasing the depth of one of the neighboring cracks by two standard deviations had a very similar failure time. On the other hand, decreasing the depth of one of the neighboring cracks by one standard deviation decelerated failure by nearly $10 \%$. Similarly, when the depth of one of the neighboring cracks was decreased by two standard deviations, a very similar result to the one standard deviation depth decrease case was observed. Other crack dimensions were also investigated in this work. For example, decreasing the radius of one of the neighboring cracks by either one or two standard deviations did not affect the failure time significantly compared to the case of having two identical cracks. Nevertheless, the spacing between the two cracks was found to have an influence on the number of cycles to achieve coalescence but not on the total cycles to failure.

The effects of different loading conditions on crack interaction, coalescence and growth process were investigated. Both experiments and simulations were performed to examine the impact of different loading conditions on cracks interaction, coalescence, growth rate and the ligament failure. A similar crack growth behavior was observed at different applied stress levels; however, higher stresses accelerated both cracks coalescence and sample failure. On the other hand, lower loading ratio yielded faster coalescence and failure.

An improved characterization of the SIF behavior at the crack front during different crack development stages was developed. It was found that increasing one of the neighboring crack depths by one or two standard deviations did not introduce major change in the SIF values. The same trend was also observed when decreasing one of the neighboring cracks depths by one or two standard deviations. Also, increasing or decreasing the radius of one of the neighboring cracks had an insignificant impact on the SIF values. On the other hand, spacing between the two cracks showed a direct impact on the SIF as smaller spacing yields a more rapid increase in the SIF values. Finally, the impact of the loading conditions on the SIF was investigated. The SIF had a very similar development behavior at different stresses before and after coalescence 
except that increasing the stress and decreasing the loading ratio accelerated failure.

It was shown that when a crack coalescence is achieved, a change is in the SIF development behavior was observed. This was attributed to the actual ligament failure when the two surface cracks coalesce and one bigger enveloping crack is formed. This sudden increase in the crack dimension causes a rapid increase in the SIF value. One of the factors affecting this ligament failure was found to be the spacing between the neighboring cracks. Neighboring cracks spacing was found to be correlated to the number of cycles to ligament failure by an exponential function. Also, it was found that higher applied stress levels and higher loading ratios had the same accelerating impact on ligament failure, however, they were both correlated to number of cycles to ligament failure by a linearly.

Finally, after characterizing how different cracks interact, coalesce and grow both experimentally and using simulation, a new probabilistic model of crack growth was developed and validated that accounts for neighboring cracks interaction and coalescence.

\section{ACKNOWLEDGEMENT}

The authors would like to thank Abu Dhabi National Oil Company (ADNOC), Abu Dhabi Company for Onshore Oil Operations (ADCO) and the Petroleum Institute (PI).

\section{NOMENCLATURE}

\begin{tabular}{|c|c|c|}
\hline PoF & Probabilistic Physics of Failure & $\Delta_{\varepsilon}$ \\
\hline LEFM & Linear Elastic Fracture Mechanics & \\
\hline EPFM & Elastic Plastic Fracture Mechanics & $P_{\text {avg }}$ \\
\hline EDM & Electric Discharge Machining & \\
\hline $\mathrm{CIF}, \gamma$ & Cracks Interaction Factor & $m_{\varepsilon}$ \\
\hline WinBUGS & $\begin{array}{l}\text { Window based computer software for } \\
\text { MCMC }\end{array}$ & \\
\hline $\mathrm{MCMC}$ & Markov chain Monte Carlo & \\
\hline SIF, K & Stress Intensity Factor & $\theta_{\mathrm{i}}$ \\
\hline Pdf & Probability density function & $\mathrm{da} / \mathrm{dn}_{\mathrm{i}}$ \\
\hline $\mathrm{a}$ & Crack depth & $\mathrm{da} / \mathrm{dn}_{\mathrm{e}, \mathrm{i}}$ \\
\hline $\mathrm{r}$ & Crack radius & \\
\hline$r_{y}$ & Plastic distance ahead of the crack tip & $\mathrm{da} / \mathrm{dn}_{\mathrm{m}, \mathrm{i}}$ \\
\hline S & $\begin{array}{l}\text { Separation distance between the inner tips } \\
\text { of the two cracks }\end{array}$ & $\mathrm{da} / \mathrm{dn}_{\text {true,I }}$ \\
\hline $\mathrm{t}$ & Sample thickness & $\mathrm{F}_{\mathrm{e}}$ \\
\hline LR & Loading ratio & \\
\hline $\mathrm{C}$ & Paris law empirical constant & \\
\hline $\mathrm{n}$ & Paris law empirical constant & $\mathrm{F}_{\mathrm{m}}$ \\
\hline$\lambda$ & $\begin{array}{l}\text { Empirical constant that indicates the } \\
\text { influence of the loading ratio on the }\end{array}$ & \\
\hline & fatigue crack growth in different materials & $b_{e}$ \\
\hline LR & Loading ratio & \\
\hline $\mathrm{N}$ & Number of cycles & $\mathrm{S}_{\mathrm{e}}$ \\
\hline a_ $(\mu / \mu)$ & $\begin{array}{l}\text { Two identical neighboring cracks notch } \\
\text { geometry; reference geometry }\end{array}$ & $b_{m}$ \\
\hline
\end{tabular}

a_ $(\mu-2 \sigma / \mu-2 \sigma)$

a_ $(\mu-2 \sigma / \mu)$
a_ $(\mu-\sigma / \mu)$
a_ $(\mu / \mu+\sigma)$
a_ $(\mu / \mu+2 \sigma)$
r_( $\mu-\sigma / \mu)$
r_( $\mu-2 \sigma / \mu)$
S_( $(\mu-\sigma)$

S_ $(\mu-2 \sigma)$

S_ $(\mu+2 \sigma)$

\begin{tabular}{|c|c|}
\hline & standard deviations \\
\hline$\Delta_{\varepsilon}$ & $\begin{array}{l}\text { Random variable of the naked eye } \\
\text { measurement error }\end{array}$ \\
\hline$P_{a v g}$ & $\begin{array}{l}\text { Average crack depth value of the repeated } \\
\text { measurements in pixels }\end{array}$ \\
\hline$m_{\varepsilon}$ & $\begin{array}{l}\text { Sizing error model parameter representing } \\
\text { the correlation between the repeated crack } \\
\text { measurements difference and the average } \\
\text { value }\end{array}$ \\
\hline$\theta_{\mathrm{i}}$ & Uncertain parameter \\
\hline $\mathrm{da} / \mathrm{dn}_{\mathrm{i}}$ & Crack growth rate true value \\
\hline $\mathrm{da} / \mathrm{dn}_{\mathrm{e}, \mathrm{i}}$ & $\begin{array}{l}\text { Crack growth rate value obtained } \\
\text { experimentally }\end{array}$ \\
\hline $\mathrm{da} / \mathrm{dn}_{\mathrm{m}, \mathrm{i}}$ & $\begin{array}{l}\text { Crack growth rate value obtained from the } \\
\text { model developed }\end{array}$ \\
\hline $\mathrm{da} / \mathrm{dn}_{\text {true,I }}$ & Corrected crack growth rate value \\
\hline $\mathrm{F}_{\mathrm{e}}$ & $\begin{array}{l}\text { The multiplicative error of the } \\
\text { experimental crack growth value with } \\
\text { respect to the true value }\end{array}$ \\
\hline $\mathrm{F}_{\mathrm{m}}$ & $\begin{array}{l}\text { The multiplicative error of the model } \\
\text { crack growth prediction with respect to } \\
\text { the true value }\end{array}$ \\
\hline$b_{e}$ & $\begin{array}{l}\text { The experimental mean multiplicative } \\
\text { error }\end{array}$ \\
\hline $\mathrm{s}_{\mathrm{e}}$ & $\begin{array}{l}\text { The Standard deviation of the } \\
\text { experimental multiplicative error }\end{array}$ \\
\hline $\mathrm{b}_{\mathrm{m}}$ & The model mean multiplicative error \\
\hline
\end{tabular}

Two identical neighboring cracks notch geometry; depth reduced by two standard deviations

Two non-identical neighboring cracks; left crack depth reduced by two standard deviations

Two non-identical neighboring cracks; left crack depth reduced by one standard deviation

Two non-identical neighboring cracks; right crack depth increased by one standard deviation

Two non-identical neighboring cracks; right crack depth increased by two standard deviations

Two non-identical neighboring cracks; left crack radius reduced by one standard deviation

Two non-identical neighboring cracks; left crack radius reduced by two standard deviations

Two identical neighboring cracks notch geometry; spacing reduced by one standard deviation

Two identical neighboring cracks notch geometry; spacing reduced by two standard deviations

Two identical neighboring cracks notch geometry; spacing increased by two standard deviations measurement error measurements in pixels

Sizing error model parameter representing the correlation between the repeated crack measurements difference and the average Crack growth rate true value Crack growth rate value obtained experimentally

Crack growth rate value obtained from the model developed experimental crack growth value with respect to the true value crack growth prediction with respect to The model mean multiplicative error 


$$
\begin{array}{ll}
\mathrm{s}_{\mathrm{m}} & \text { The standard deviation of the model } \\
\text { multiplicative error }
\end{array}
$$

\section{REFERENCES}

Ahmad, Z. (2007). Corrosion Fatigue . In Principles of Corrosion Engineering and Corrosion Control (pp. 221241). Elsevier.

Al Tamimi, A. (2014). Improved probabilistic remaining useful life estimation in engineering structures: modeling multi-site fatige cracking, PhD Thesis. College Park: University of Maryalnd.

Al Tamimi, A., \& Modarres, M. (2014). Coalescence and Growth of Two Semi-elliptical Coplanar Cracks in API-5L Grade B steel . SEM 2014 Annual Conference \& Exposition on Experimental and Applied Mechanics. Greenville, SC, USA.

Alabama Specialty Products. (2014). (Metal Samples ) Retrieved from http://www.alspi.com/MS-machining.htm Alseyabi, M. C. (2009). Structuring a Probabilistic Model for Reliability Evaluation of Piping Subject to Corrosionfatigue Degredation, PhD thesis. College Park: University of Maryland.

ASME. (1992). Rules for inservice inspection of nuclear power plant components. In Boiler and Pressure Vessel Code (pp. Appendix A, Section XI). ASME.

Azarhkail, M., \& Modarres, M. (2007). Markov chain Monte Carlo simulation for estimating accelerated life model parameters. Annual Reliability and Mainitainability Symposium (RAMS) Proceedings. Orlando.

Azarkhail, M., \& Modarres, M. (2007). A Novel Bayesian Framework for Uncertainity Management in Physics-Based Reliability Models. ASME International Mechanical Engineering Congress and Expositon. Seattle, Washignton, USA.

Azarkhail, M., \& Modarres, M. (2012). The Evolution and History of Reliability Engineering: Rise of Mechanistic Reliablity Modeling. International Journal of Performability Engineering , 8, 35-47.

Azarkhail, M., Ontiveros, V., \& Modarres, M. (2009). A Bayesian Framework for Model Uncertainity Consideration in Fire Simulation Codes. 17th International Conference on Nuclear Engineering . Brussels.

Bayley, C. (1997). Parametric Investigation on the Coalescence of Coplanar Fatigue Cracks, Masters' thesis. Ottawa: Carelton University .

Beretta, S., Carboni, M., Cantini, S., \& Ghidini, A. (2004). Application of fatigue crack growth algorithms to railway axles and comparison of two steel grades. Journal of Rail and Rapid Transit, 218 (4), 317-326.

BSI. (1991). Guidance on methods for assessing the acceptability of flaws in fusion welded joints. British Standard Institute.
Carlton, R., Lyman, c., \& Roberts, J. (2004). Accuracy and Precision of Quantitative Energy Dispersive X-ray Spectrometry in the Environmental Scanning Electron Microscope. Scanning 26, 167-174.

Cavanaugh, J. (2012, September 25). Lecture V: The Bayesian Information Criterion. (University of Iowa) Retrieved August 29, 2014, from http://myweb.uiowa.edu/cavaaugh/ms_lec_5_ho.pdf

Chang, R. (1982). On Crack-Crack Interaction and Coalescence in Fatigue . Engineering Fracture Mechanics, 16, 683-693.

Chaussumier, M., Shahzad, M., Mabru, C., Chieragatti, R., \& Rezai-Aria, F. (2010). A Fatigue Multi-Site Cracks Model Using Coalescence, Short and Long Crack Growth Laws, for Anodized Aluminum Alloys.

Cortie, M., \& Garrett, G. (1988). On the correlation between the $\mathrm{C}$ and $\mathrm{m}$ in the Paris equation for fatigue crack propagation. Engineering Fracture Mechanics , 30 (1), 4958.

DeBartolo, E., \& Hillberry, B. (1998). Effects of Constituent Particle Clusters on Fatigue Behavior of 2024T3 Aluminum Alloy . Int. J. Fatigue, 20, 727-735.

Dowling, N., Calhoun, C., \& Arcari, A. (2008). Mean stress effects in stress-life fatigue and the Walker equation. Fatigue and Fracture of Engineering Materials and Structures , 32, 163-179.

Dwivedi, P., \& Green, D. (1995). Indentation Crack Shape Evolution During Subcritical Crack Growth. Journal of the American Ceramic Society, 78 (5), 1240-1246.

Erdogan, F. (1962). On the stress distribuion in plates with collinear cuts under arbitary loads. 4th US Nat. Cong. Appl. Mech., (pp. 547-53). PP. 547-553.

Ewalds, H., \& Wanhill, R. (1984). The three modes of loading. Retrieved November 1, 2013, from http://thediagram.com/12_3/thethreemodes.html

Fatemi, A. (n.d.). Fundamentals of LEFM and Applications to Fatigue Crack Growth, Chapter 6. Toledo: University of Toledo.

Fernandes, J. (2002). Uma metodologia para a analise $e$ modelagem, PhD thesis. Rio de Jeneiro, Brasil: PUC.

Forsyth, P. (1983). A unified Description of Micro and Macro-scopic Fatigue Crack Behaviour . International Journal of Fatigue , 5, 3-14.

Georgsson, P. (2000). The determinatino of uncertainties in fatigue crack growth measurements. Trollhattan, Sweden : Volvo Aero Corporation .

Hamam, R., Pommier, S., \& Bumbieler, F. (2007). Variable amplitude fatigue crack growth, experimental results and modeling . 29 (1634-1646).

Harrington, D. (1995). Fatigue Crack Coalescence and Shape Development and Experimental Invistigation, Masters Thesis. Carleton University, Department of Mechanical and Aerospace Engineering .

Ho, K., \& Newman, S. (2003). State of the Art Electrical Discharge Machining (EDM). International Journal of Mchine Tools and Manufacture , 43 (13), 1287-1300. 
Iida, K. (1983). Shapes and Coalescence of Suface Fatigue Cracks. I.C.F. International Symposium on Fracture Mechanics. Beijing.

Irwin, G. (1962). Crack Extension Force for a Part Through Crack in a Plate. Journal of Applied Mechanics , 29, 651654.

ISO TAG4. (1993). In Guide to the expression of uncertainty in measurement (pp. ISBN 92-67-10188-9). Geneva, Switzerland: International Organization for Standardisation.

Keshtgar, A. (2013). Acoustic emission-based structural health management and prognostics subject to small fatigue cracks, PhD thesis . College Park: University of Maryland.

Keshtgar, A., \& Modarres, M. (2013). Detection of crack intitation based on acoustic emission. Chemical engineering 33 , DOI: 10.3303/CET1333092.

Keshtgar, A., \& Modarres, M. (2013). Probabilistic model developement for fatigue crack detection using acoustic emission technology. International Topical Meeting on Probabilistic Safety Assesement and Analysis. Columbia, SC: ANS PSA.

Kishimoto, K., Soboyejo, W., Smith, R., \& Knott, J. (1989). A Numerical Invistigation of the Interaction and Coalescence of Twin Coplanar Semi Elliptical Fatigue Cracks. International Journal of Fatigue , 11 (2), 91-96.

Krishnaprasad, K., \& Prakash, V. (2009). Fatigue crack growth behavior in dissimilar metal weldment of staniless steel and carbon steel. World Academy of Science, Engineering and Technology , 3, 8-22.

Leek, T. (1990). The Interaction and Growth of Two Surface Cracks Under Fatigue Loading, PhD Thesis. UK: University of Sheffield.

Leek, T., \& Howard, I. (1996). An examination of methods of assessing interacting surface crack by comparison with experimental data. International Journal of Pressure Vessels and Piping , 181-201.

Leek, T., \& Howard, I. (1996). An Examination of Methods of Assessing Interacting Surface Cracks by Comparison with Experimental Data. International Journal of Pressure Vessels and Piping , 68, 181-201.

Leek, T., \& Howard, I. (1994). Estimating the Elastic Interaction Factors of Two Coplanar Surface Cracks Under Mode I load. International Journal of Pressure Vessels and Pipeing , 60, 307-321.

Leek, T., \& Howard, I. (1994). Rules for the Assessment of Interacting Suface Cracks Under Mode I Load. Internationl Journal of Pressure Vessels and Piping , 60, 323-339.

Li, C. (1996). Probabilistic Modeling for Corrosion-Fatigue Crack Growth, PhD Dissertation. Lehigh University .

Lin, X., \& Smith, R. (1995). Numerical Prediction of Fatigue Crack Growth of a Surface Defect. Fatigue and Fracture of Engineering Materials and Structures , 18 (2), 247-256.

Materials Evaluation and Engineering Inc. (2009). Energy Dispersive $X$-ray Spectroscopy. (Materials Evaluation and
Engineering, Inc.) Retrieved December 02, 2013, from http://mee-inc.com/eds.html

Melin, S. (1983). Why do Cracks Avoid Each Other. International Journal of Fracture , 23, 37-45.

Modarres, M. (2012). Accelerated Life Testing, ENRE64, Class Presentation Slides . College Park: University of Maryland.

Modarres, M. (2008). Accelerated Testing, ENRE 641. College Park : Center of Risk and Reliability, UMD, College Park, USA.

Modarres, M., Kaminskiy, M., \& Krivtsov, V. (2010). Reliability engineering and risk analysis. CRC Press.

Murakami, Y., \& Nemat-Nasser, S. (1982). Interacting Dissimilar Semi-elliptical Surface Flaws Under Tension and Bending . Engineering Fracture Mechanics , 16, 373-386.

Murakami, Y., \& Nisitani, H. (1981). Stress Intensity Factors for Interacting Two Equal Semi-elliptical Surface Cracks in Tension. Trans. Japan Soc. Mech. Engrs SerA, 47, 295-303.

National Research Council. (2013). Effects of Diluted Bitumen on Crude Oil Transmission Pipeline, Special Report 311. National Research Council.

Neves Beltrao, M., Castrodeza, E., \& Bastian, F. (2010). Fatigue crack propagation in API 5L X-70 pipeline steel longitudinal welded joints under constant and variable amplitude. Fatigue and Fracture of Engineering Materials and Structures , 34, 321-328.

Newman, J. (1979). A Review and Assessment of the Stress Intensity Factors for Surface Cracks. ASTM STP 687.

Newman, J., \& Raju, I. (1981). An Emperical Stress Intensity Factor Equation for the Surface Crack. Engineering Fracture Mechanics, 15.

Newman, J., \& Raju, I. (1984). Stress Intensity Factor Equations for Cracks in Three Dimensional Finite Bodies Subjected to Tension and Bending Loads. Hampton, Virginia: NASA.

Newman, J., \& Raju, I. (1979). Stress intensity Factors for a Wide Range of Semi-Elliptical Suface Cracks in Finite Width Plates. Engineering Fracture Mechanics , 11.

Nuhi, M., Abu Seer, T., Al Tamimi, A., Modarres, M., \& Seibi, A. (2011). Reliability Analysis for Degredation Effects of Pitting Corrosion in Carbon Steel Pipes. ICM11. Como .

O'Donoghure, T., Nishioka, P., \& Atluris, N. (1984). Multiple Surface Cracks in Pressure Vessels. Engineering Fracture Mechanics , 20 (3), 545-560.

Ontiveros, V., Cartillier, A., \& Modarres, M. (2010). An Integrated Methodology for Assessing Fire Simulation Code Uncertainity. Nuclear Science Engineering , 166, 179-201.

Paris, P., \& Erdogan, F. (1963). A critical analysis of crack propagation laws . Journal of Basic Engineering , 528-534.

Pitt, S., \& Jones, R. (1997). Multiple-Site and Widespread Fatigue Damage in Aging Aircrafts. Engineering Failure Analysis , 4, 237-257. 
Roberge, P. (2012 ). Corrosion Pit Shapes. (Corrosion Doctors ) Retrieved June Tuseday, the 26th , 2012, from http://corrosion-doctors.org/Forms-pitting/shapes.htm

Savin, G. N. (1981). Stress concentration around holes. Oxford: Pergamon Press.

Shi, Y., Chen, B., \& Zhang, J. (1999). Effects of welding residual stresses on fatigue crack growth behaviour in butt welds of a pipline steel. Engineering Fracture Mechanics, 36, 893-902.

Soboyejo, W., \& Knott, J. (1990). Fatigue Crack Propagation of Copalanr Semi-elliptical Cracks in Pure Bending. Engineering Fracture Mechanics , 37 (2), 323340.

Spiegelhalter, D., Thomas, A., Best, N., \& Lunn, D. (2003). WinBUGS 1.4 manual .

Stephens, R., Fatemi, A., Stephens, R., \& Fuchs, H. (2000). Metal fatigue in engineering. John Wiley \& Sons .

Terrell, J. (1988). Effect of Cyclic Frequency on the Fatigue Life of ASME SA-106-B Piping Steel in BWR Environments. Journal of Material Engineering , 10, 193203.

Twaddle, J., \& Hancock, B. (1988). The Development of Cracks by Defect Coalescence. Engineering Materials Advisory Service , 185-198.

Willard, S. A. (1997). Use of of Marker Bands for Determination of Fatigue Crack Growth Rates and Crack Front Shapes in Pre-Corroded Coupons. Hampton, Virginia : NASA.

Yokobori, T., Ohashi, M., \& Ichikawa, M. (1965). The interaction of two collinear asymmetrical elastic cracks. Vol. 1, PP. 33-39: Tohoku University .

Zhang, H. (1993). Fatigue Crack Growth and Coalescence Study. Ontario: Carleton University.

\section{BIOGRAPHIES}

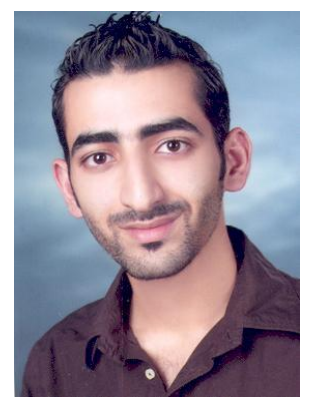

Abdallah Al Tamimi is a mechanical engineer and a $\mathrm{PhD}$ graduate of the reliability engineering program, University of Maryland, College Park, USA. He earned his mechanical engineering degree from the Petroleum Institute, Abu Dhabi, United Arab Emirates. Also, he earned both his Master's and $\mathrm{PhD}$ in Reliability engineering from the University of Maryland, College Park, United States. Over the last four years, he has worked in a variety of professional organizations in both academia and the oil and gas industry. He worked in Abu Dhabi Marine Operating Company (ADMA-OPCO) as a mechanical supervisor. Afterwards, he made his transition to academia by working as a teaching assistant at the Petroleum Institute. During his last year of $\mathrm{PhD}$, he was the Mechanics and Reliability laboratory manager. He started his $\mathrm{PhD}$ studies in reliability engineering in 2011 after he was granted a fellowship by Abu Dhabi National Oil Company (ADNOC) and was able to complete both his Masters and $\mathrm{PhD}$ degrees requirements in three years.

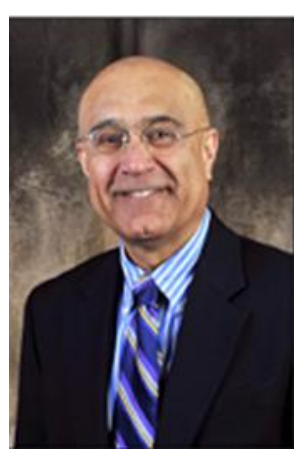

Mohammad Modarres is the Director of Reliability Engineering and Minta Martin Professor of Engineering in the University of Maryland, College Park, United States. He specializes in probabilistic risk assessment and management, uncertainty analysis, probabilistic physics of failure and probabilistic fracture mechanics modeling. He earned his B.S. degree from Tehran Polytechnic in mechanical engineering, a Master's degree from Massachusetts Institute of Technology in mechanical engineering and a PhD from Massachusetts Institute of Technology in nuclear engineering. He has served as a consultant or board member to several governmental agencies including the Nuclear Regulatory Commission, Department of Energy, National Academy of Sciences, and several national laboratories in areas related to nuclear safety, probabilistic risk assessment, probabilistic fracture mechanics and physics of failure. He has over 300 papers in archival journals and proceedings of conferences. He has published a number of textbooks, edited books and book chapters in various areas of nuclear safety, risk and reliability engineering. $\mathrm{He}$ is a University of Maryland Distinguished Scholar-Teacher and a fellow of the American Nuclear Society. 